\title{
The Employment Effect of Reforming a Public Employment Agency
}

\author{
Andrey Launov ${ }^{a), b), c)}$ and Klaus Wälde ${ }^{a), b), c), 1}$ \\ a) Department of Economics, University of Mainz, Jakob-Welder-Weg 4, 55128 Mainz, Germany \\ ${ }^{b)}$ Department of Economics (IRES), Université catholique de Louvain, Place Montesquieu 3, \\ 1348 Louvain-la-Neuve, Belgium \\ ${ }^{c)}$ CESifo, Center for Economic Studies, Schackstr. 4, 80539 Munich, Germany
}

August 2015

By how much does an increase in operating effectiveness of a public employment agency (PEA) and a reduction of unemployment benefits reduce unemployment? Using a recent labour market reform in Germany as background, we find that an enhanced effectiveness of the PEA explains about $20 \%$ of the observed postreform unemployment decline. The role of unemployment benefit reduction explains just about $5 \%$ of the observed decline. Due to disincentive effects resulting from the reform, the reform of the PEA could have had an even higher impact on unemployment reduction if there had been less focus on long-term unemployed workers.

JEL Codes: E24, J65, J68

Keywords: Employment agencies, unemployment benefits

labour market reform, unemployment, structural model

\footnotetext{
${ }^{1}$ Andrey Launov [corresponding author] : Department of Economics, University of Mainz, Jakob-WelderWeg 4, 55128 Mainz, Germany, andrey.launov@uni-mainz.de, phone + 49-6131-39-23233. Klaus Wälde: waelde@uni-mainz.de, www.waelde.com, phone + 49-6131-39-20143.
} 


\section{Introduction}

Understanding the determinants of unemployment has always been at the center of economic research and public interest alike. This is true in "old times" when oil price shocks hit OECD countries, just as much as today in the aftermath of the financial crisis.

It is widely accepted by now that labour market institutions such as the unemployment benefit system, trade unions, minimum wages, employment protection legislation and labour taxes stand among key determinants of unemployment in OECD countries (see e.g. Blau and Kahn, 1999, and Nickell and Layard, 1999). Despite their apparent heterogeneity, all these institutions have one salient trait in common: whatever the degree of coordination frictions, they shape the incentives of the market participants. Just in contrast to that stands another important labour market institution: the public employment agency. Whatever the incentives of the market participants, public employment agencies reduce the degree of coordination frictions (Petrongolo and Pissarides, 2001).

While employment effects of unemployment benefits, unions, employment protection and taxation have been quite extensively studied to this date, there is surprisingly little evidence on the role of a public employment agency (PEA) in reducing equilibrium unemployment. The present paper fills this gap.

We use the unique setup of a comprehensive labour market reform introduced between 2003 and 2005 in Germany. This reform induced an increase in operating effectiveness of the Federal Employment Agency (a PEA) and reduced the generosity of payments to the unemployed. ${ }^{2}$ We structurally estimate the effect of the increase of operating effectiveness on the equilibrium unemployment rate. We then compare this impact with the impact of the reduction of unemployment assistance benefits. We find that organizing the work of a PEA in a more efficient way has scored a much better result than creating pecuniary incentives through unemployment assistance benefits. Quantitatively, the re-organization of the agency is responsible for a 0.69 to 0.88 percentage point drop of the equilibrium unemployment rate, explaining $17.7 \%$ to $22.5 \%$ of the observed post-reform decline in unemployment. Benefit reduction, in contrast, adds only 0.18 to 0.20 percentage points to the fall of the equilibrium unemployment rate. This explains merely $4.6 \%$ to $5.1 \%$ of the observed post-reform unemployment decline.

Furthermore, and somewhat surprisingly, we find an "unemployment paradox": An increase in effectiveness of a PEA can lead to an increase of the unemployment rate. An ambiguous response of the unemployment rate to the reform can arise, for instance, if the reform design favours long-term unemployed workers more than short-term ones. When a PEA becomes more effective in matching the long-term unemployed, search effort and hence exit rates of long-term unemployed workers go up. Short-term unemployed workers anticipate this increase in the exit rate and therefore have less incentives to search intensively while still being short-term unemployed. Consequently, search effort and exit rates of the short-term unemployed go down. As long as the disincentive effect on the short-term unemployed workers is stronger than the positive influence on the long-term unemployed workers, the unemployment rate rises when the PEA becomes more productive.

\footnotetext{
${ }^{2}$ We use the term effectiveness to denote total factor productivity of the matching function. This differs from individual search productivity. See our model specification below for details.
} 
Quantitatively, we indeed find that the reform's focus on long-term unemployed workers weakened the overall intended goal. If the increase in matching effectiveness of the agency for the long-term unemployed workers had been just as high as the (smaller) increase in effectiveness for the short-term unemployed, the reform would have reduced the equilibrium unemployment rate by further 0.21 percentage points. Apparently, the extra increase of matching efficiency for the long-term unemployed workers was too much of a good thing.

Our model shares a number of elements with the existing search and matching literature. Workers are ex-ante heterogeneous in skills, as in Mortensen and Pissarides (1999) and PostelVinay and Robin (2002), and ex-post heterogeneous in duration of their unemployment spells. The model allows for time-dependent unemployment benefits, as in Albrecht and Vroman (2005) and Coles and Masters (2006), to capture the differences between unemployment insurance (UI) and unemployment assistance (UA) payments. Benefits are proportional to past wages, as in Chéron and Langot (2010), and there is a fixed time limit on UI. Workers optimally choose search effort, as in Cahuc and Lehmann (2000) and Lehmann and van der Linden (2007), and experience negative duration dependence of their exit rates out of unemployment due to Bayesian learning. The simultaneous presence of a duration-contingent effectiveness of the PEA and time-dependent unemployment benefits in our model allows for an easy comparison of the equilibrium effects of the reforms of these two institutions.

The setup closest to this paper is our earlier equilibrium analysis of nonstationary search and matching (Launov and Wälde, 2013). From a theoretical perspective, we extend this model to allow for a matching effectiveness of the public employment agency that changes due to a reform and that varies with duration of unemployment. This theoretically tiny extension has dramatic implications for policy evaluation. First, we are able to talk about the effects of the Hartz III reform (which is not possible in our earlier work). Second, we are able to identify and analyse the unemployment paradox. Third, we quantify this effect here (and slightly amend our earlier estimates of the Hartz IV reform) using a novel estimation procedure.

To quantify the employment effect of the reform of the PEA in Germany we estimate our theoretical model using the following two-stage procedure. At the first stage we estimate all parameters of the pre-reform steady state from the pre-reform data, keeping matching effectiveness parameters of the agency for short- and long-term unemployed workers normalized to unity. Estimation at the first stage is fully structural, by maximum likelihood, as e.g. in Ridder and van de Berg (1998). The data are the survey data on individual employment histories taken from the German Socio-Economic Panel. At the second stage we use both pre-reform and post-reform data to estimate the reform-induced increase of the matching effectiveness of PEA for short- and long-term unemployed, taking the estimates from the first stage as given. Estimation at the second stage is again fully structural, using indirect inference as e.g. in Lise (2013) and Bagger et al. (2014). The data are the regional time series data on matches, vacancies and unemployment collected by the Institute for Employment Research (IAB, Nürnberg). Auxiliary regressions at the second step match the impact coefficient of the reform of the PEA on log-matches for short- and long-term unemployed workers. ${ }^{3}$ The entire two-step approach is similar to the one of Postel-Vinay and Turon (2010). Estimated increases of the effectiveness of the agency due to the reform of the PEA

\footnotetext{
${ }^{3}$ Fahr and Sunde (2009) and Klinger and Rothe (2012) use similar regressions to assess the reform.
} 
immediately lead to the change in equilibrium unemployment caused by this reform.

To the best of our knowledge, our paper is the first to estimate the equilibrium employment effect of a reform of a PEA. The closest papers to ours in the structural literature on employment agencies are Pissarides (1979) and Fougère et al. (2009). Pissarides (1979) considers a theoretical equilibrium search model in which unemployed workers can obtain job offers either via a PEA, or via a PEA and through private search. Both search channels are costly to workers and a match via PEA is costly to firms. Pissarides (1979) shows that his model displays what could be called a "public-private unemployment paradox": An improvement of the matching technology of the PEA can increase the aggregate unemployment rate. Fougère et al. (2009) set up a one-sided empirical job search model to evaluate the optimal private search effort when the PEA provides job offers at an exogenous rate and when private search is costly. Their model likewise implies a public-private unemployment paradox. Estimating their model with French data, however, they find that a more productive PEA clearly increases exit from unemployment.

Even though our model does not include private search, we still obtain an unemployment paradox. Ours is intertemporal in nature, being a consequence of the heterogenous change of the agency's matching effectiveness for long-term and short-term unemployed workers and the anticipation by the short-term unemployed workers. Going beyond these two papers, we also evaluate the impact of a real-life reform of a PEA and emphasize the importance of an improved PEA relative to changes in unemployment benefits.

Other papers related to our analysis include Jung and Kuhn (2014) and Krebs and Scheffel (2014). Jung and Kuhn (2014) show that low effectiveness of a PEA in matching unemployed with vacant jobs is largely responsible for the difference in "ins" and "outs" of unemployment between Germany and the US in the 1980s and 90s. Krebs and Scheffel (2014) argue that an increased effectiveness of a PEA reduces the cost of recessions. ${ }^{4}$

Our paper also contributes to two further strands of the literature that deal with labour market policies and institutions. First, we add to the structural literature which quantifies the employment effect of institutions. To give a few recent examples of this literature, Yashiv (2004) and Pries and Rogerson (2005) simulate the individual and joint impact of a wide array of institutions, such as unemployment insurance, hiring subsidy, labour taxes and minimum wages. Cahuc and Malherbet (2004) calibrate the employment effect of an experience-rated system of financing unemployment benefits. Immervoll et al. (2007) perform microsimulations on the influence of in-work benefits and L'Haridon and Malherbet (2009) look into the effect of employment protection through layoff tax and payroll subsidy. Boeri and Burda (2009) investigate the impact of endogenous coverage of collective bargaining and Bentolila et al. (2012) assess the role of temporary contracts and firing costs. Finally, Flinn (2006) sets up structural estimation of the employment effect of a minimum wage and Launov and Wälde (2013) do the same for the length and level of unemployment benefits. We contribute to this literature by evaluating - as we show - a very important institution which, surprisingly, has been largely overlooked so far. This institution is the PEA itself.

Second, we add to the existing reduced-form econometric literature on the effectiveness of PEAs as compared to other search methods. This literature predominantly follows the

\footnotetext{
${ }^{4}$ More distantly related articles comprise Plesca (2010), who sets up a model with directed search through agencies, and Yavaş (1994), who views agencies as middlemen.
} 
pioneering contributions of Holzer (1988) and Blau and Robins (1990), considering a multitude of job search techniques used by unemployed workers. ${ }^{5}$ Conclusions on the effectiveness of the agency in this literature vary. Yet, irrespective of the conclusions, its reduced-form nature makes it hard to infer about the effect of the PEA on the equilibrium unemployment rate. We contribute to this literature by looking beyond the simple significance of the agency and estimate its equilibrium impact on the dynamics of unemployment.

The paper is organized as follows. Section 2 presents stylized facts about German unemployment and provides a detailed description of the comprehensive labour market reform of 2003-2005 (the so-called Hartz reforms). Section 3 describes the theoretical model we use to reach all of our conclusions. It also works out the ambiguity of the impact of the reform of a PEA under a heterogeneous increase of matching effectiveness for short- and long-term unemployed workers. Section 4 lays out the structural estimation procedure, discusses the estimation results, analyses the effect of an improvement of a PEA relative to a reduction of unemployment benefits and conducts sensitivity analyses. Section 5 concludes.

\section{Labour market reforms in Germany}

\subsection{Stylized facts}

Like many large continental European countries, Germany has been experiencing a steady increase in unemployment ever since the early 1970s. As Figure 1 shows, this rise continued in Germany until early $2005 .{ }^{6}$
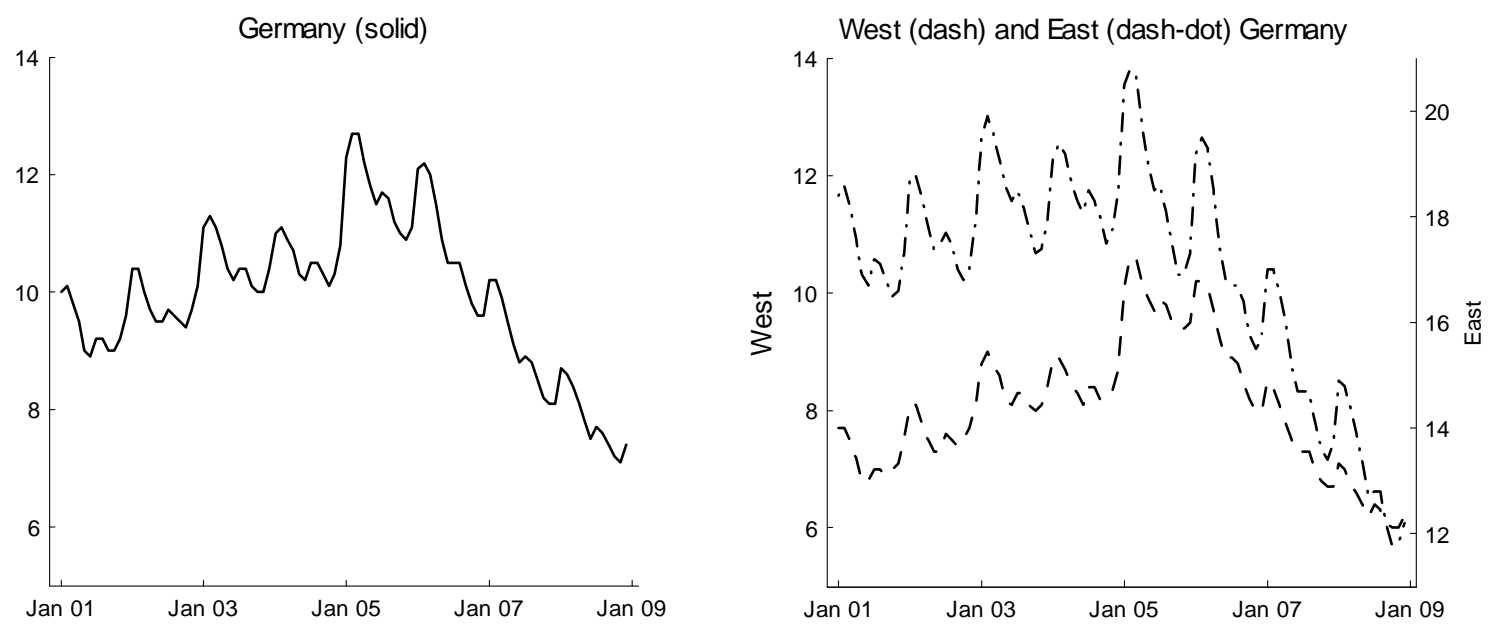

Figure 1 Monthly unemployment rate around the time of the Hartz reforms (data source: Bundesagentur für Arbeit)

\footnotetext{
${ }^{5}$ See Weber and Mahringer (2008) for a recent application and summary of this literature over the preceding twenty years.

${ }^{6}$ The increase leading to the peak in January 2005 is higher than in other years. This is related to a structural break in unemployment statistics, as from January 2005 onwards all former recipients of welfare payments had to register as being unemployed in order to be eligible to benefit payments.
} 
The absence of any persistent reversal by the 2000s called for a restructuring of the (supposedly) generous institutions of the welfare state. The long awaited political response has arrived with a comprehensive labour market reform: the Hartz reform. The reform has been introduced step by step between 2003 and 2005. It consisted of four different packages (Hartz I to IV) which affected nearly all aspects of the German labour market. It is remarkable that its third package (Hartz III) was almost exclusively devoted to reorganizing the operation of the Federal Employment Agency, while its last package (Hartz IV) focused almost exclusively on the monetary compensation scheme for the unemployed workers.

As of March 2005, a strong decline in unemployment has set in. This applies both to Germany as a whole (left panel of Figure 1) and to East and West Germany separately (right panel). In terms of numbers, between the introduction of Hartz IV and the onset of the Great Recession, the unemployment rate in Germany has gone down from $11.7 \%$ in 2005 to $7.8 \%$ in 2008 , i.e. by 3.9 percentage points. The same applies to East and West Germany with 5.6 and 3.5 percentage points reduction, respectively.

\subsection{Institutional framework of the reform}

The Hartz reform has been designed to substantially refurbish the institutional organization of the German labour market, affecting nearly all of its facets.

To give a clear idea of what is the place of the two institutions of our interest, namely the PEA and unemployment benefits, in the entire set of policy measures introduced, we provide a brief overview of all core packages of the Hartz reform (for details on the corresponding literature, see Appendix A.1).

Hartz I has launched a considerable variety of employment-stimulating programmes and flexible forms of work. It has also established personnel service agencies which serve as intermediaries between job searchers and employers offering temporary (subcontracted) work placement. It has furthermore introduced training vouchers to take advantage of occupational training and implemented special rules for job market integration of workers over 50 years of age. On top of that, Hartz I has strengthened sanctions in case of voluntary job quits, rejection of suitable offers and aborting training programs or temporary work placement. This package has become effective as of January 2003.

Hartz II has re-organized marginal employment represented by so-called "mini-" and "midijobs". Workers in minijobs were allowed to earn up to EUR 400 tax-free per month. A linear tax rule was introduced for midijobs paying up to EUR 800 per month. Hartz II has also modified the program for start-up subsidies to enhance transitions to self-employment. It became effective simultaneously with Hartz I.

Hartz III has laid out the internal administrative reform of the Federal Employment Agency as an entity. It has brought in a set of new regulations and revised the distribution of responsibilities within the agency. Most importantly, all claims by an unemployed worker have now become processed by a single case-worker. Further, limits on the number of cases supervised by a single case-worker were introduced. Along with importance grading of cases, this has allowed to increase contact time per unemployed worker. Another important feature of this package was the provision of separate advice for short- and long-term unemployed workers. Hartz III has also reduced the weight of active labour market programs. It has become effective as of January 2004. 
Hartz IV has abolished the proportionality of the former UA benefits to previous net earnings. Fixed UA benefits (called Arbeitslosengeld II; ALG II) were introduced instead, low enough to generate a reduction of assistance payments on average. Hartz IV has furthermore reduced the duration of entitlement to UI benefits (now called Arbeitslosengeld I; ALG I) for workers over 45. Severity of this reduction of entitlement duration increased with age. This package has become effective as of January 2005.

This overview shows why looking at the Hartz reform is interesting if one wants to estimate the effect of a reform of a PEA and compare it to the effect of a reform of an unemployment benefit system. The third package of this reform (Hartz III) almost entirely deals with the reorganization of the agency. ${ }^{7}$ Furthermore, implementation of Hartz III did not coincide with any other policy change assumed by the Hartz reform. Reduction of unemployment benefit generosity, in its turn, was the central objective of the fourth package (Hartz IV). Just like with the preceding package, no other policy change has been implemented together with this benefit reduction.

It should be noted that there were also elements of PEA improvements, namely the introduction of personnel service agencies and strengthening of sanctions, in the first package of the Hartz reforms. However PEA-related components of Hartz I were only a small fraction of the entire package and the composition of Hartz I is too complex to allow identification of these components within the entire spectrum of the package policies. Moreover Hartz I and II were implemented simultaneously, which complicates matters even further. For this reason we will take a conservative stance and measure the effect of the reform of the PEA by the effect of Hartz III exclusively.

\section{Theory}

\subsection{The model}

We formulate a Mortensen-Pissarides matching model with duration-contingent effectiveness of a PEA in matching unemployed workers with vacant jobs and duration-dependent unemployment benefit payments. Workers in our model are risk averse and ex ante heterogeneous with respect to observed skills and unobserved search productivities. Firms operate within skill-specific markets, each opening a vacancy for a particular skill level. Wages are set by collective bargaining and the government runs a balanced budget by financing unemployment benefits through the labour tax. As such, our model is based on a model of Launov and Wälde (2013) extended for duration-contingent matching effectiveness of the agency. This extension provides a unified framework that allows us to understand the effects of the PEA reform and compare these to the effect of a reform of the benefit system. ${ }^{8}$

\footnotetext{
${ }^{7}$ While there were also some sanctions introduced under Hartz III, they were negligible in duration. At the harshest, benefits could be revoked for two weeks if an individual does not show enough commitment.

${ }^{8}$ For the time being we refrain from including a private search channel (as in Pissarides, 1979 or Fougère et al., 2009) in our analysis. Adding private search, we would expect that discouraged search of short-term unemployed via the PEA would encourage their search via the private channel. This would counteract the Pissarides effect and bring along another ambiguous effect on the unemployment rate. We believe this is worth being studied in future work.
} 
- Matching effectiveness of the agency

Given the heterogenous approach to short- and long-term unemployed workers by the Hartz III reform we consider the following duration dependence in matching effectiveness of the PEA. Let $s$ denote the duration of unemployment and let $\bar{s}$ denote the duration of entitlement to UI benefits. An unemployed worker is called short-term unemployed if $0 \leq s \leq \bar{s}$ and long-term unemployed if $s>\bar{s}$. The duration-contingent effectiveness of the $\mathrm{PEA}$ is given by

$$
\psi(s)=\left\{\begin{array}{l}
\psi^{U I}, \text { for } 0 \leq s \leq \bar{s} \\
\psi^{U A}, \text { for } s>\bar{s}
\end{array}\right.
$$

The function $\psi(s)$ reflects both pre- and post-Hartz III institutional environments. Before the Hartz III reform $\psi(s)$ is equal to unity irrespective of $s$. It takes values larger than one after the reform. Due to differential treatment of short- and long-term unemployed by Hartz III post-reform values of $\psi^{U I}$ and $\psi^{U A}$ are not equal to each other. Theoretically speaking, there are no restrictions on effectiveness, i.e. $\psi^{U I} \gtreqless \psi^{U A}$.

The function $\psi(s)$ directly enters the individual exit rate from unemployment as shown below in (3). Estimation of its post-reform values is the key problem of the present paper.

- Unemployment benefit system

Our model replicates the statutory two-step unemployment compensation system with UI benefits $\left(b_{U I}\right)$, UA benefits $\left(b_{U A}\right)$ and the time limit on UI benefits. With $s$ and $\bar{s}$ as defined above, the benefits in our model are given by

$$
b(s)=\left\{\begin{array}{l}
b_{U I}, \text { for } 0 \leq s \leq \bar{s} \\
b_{U A}, \text { for } s>\bar{s}
\end{array}\right.
$$

where $b_{U I}>b_{U A}$. This system likewise reflects both pre- and post-Hartz IV institutional environments. Before the reform both $b_{U I}$ and $b_{U A}$ are proportional to the net wage paid by the last job. After the reform $b_{U A}$ is replaced by the fixed ALG II amount.

Eligibility to UA benefits is means tested, with $\pi^{U A}$ denoting the individual's probability (from the econometrician's viewpoint) of passing the means test. As means tests relate to family income and further individual circumstances, which are usually known to workers beforehand, workers know with certainty whether they will pass this test.

- Workers

Workers are ex ante heterogeneous with respect to skills and search productivity. Both skill level and search productivity level are innate and remain constant throughout the whole working life. The skill distribution $\{\pi(k)\}_{k=1}^{K}$ takes $K$ distinct levels and is known to the worker upon entry into the market. The distribution of search productivity takes two distinct levels: 'low' and 'high', where $\pi^{\chi}$ is the population share of high-productive workers. An unemployed worker of skill $k$ does not know with certainty how productive she is in search. Instead, at the beginning of each unemployment spell she has a prior belief about being a high-productive type. We denote this initial subjective probability of being a high-productive 
type by $p_{k}(0)$. This probability will be updated in a Bayesian fashion throughout the unemployment spell as described in (14) below. ${ }^{9}$

Unemployed workers of skill $k$ receive benefits $b(s)$ and exert search effort $\phi_{k}(s)$ to look for jobs. Instantaneous utility $v\left(b(s), \phi_{k}(s)\right)$ strictly increases in benefits and strictly decreases in search effort. We assume that the instantaneous utility function takes a CRRA form, ${ }^{10}$

$$
v\left(b(s), \phi_{k}(s)\right)=\frac{1}{1-\sigma}\left[b(s)^{1-\sigma}-1\right]-\phi_{k}(s) .
$$

While search effort brings disutility, it also increases the chances of contact with a vacancy available on the corresponding skill market. Contacts with firms arrive to workers at the (objective) rate

$$
\mu_{k}(s, \chi)=\left((1-\chi) \eta_{0, k}+\chi \eta_{1, k}\right) \psi(s)\left[\phi_{k}(s) \theta_{k}\right]^{\alpha}, \quad \eta_{1, k}>\eta_{0, k}>0 \forall k .
$$

In this expression $\chi$ is an indicator variable that takes the value of 1 if the worker is highproductive in search (and $\chi=0$ if low-productive); $\eta_{0, k}$ and $\eta_{1, k}$ are the skill-specific search productivity parameters of the contact rate of low- and high-productive types, respectively; $\alpha$ is the shape parameter of the contact rate, with $\alpha \in(0,1)$ such that returns to search effort are diminishing; $\theta_{k}$ is the tightness, i.e. vacancy-to-unemployment ratio, at the skillspecific market $k$. The matching effectiveness of the PEA, $\psi(s)$, enters the contact rate as an additional scale parameter, just as the search-type of an individual. ${ }^{11}$

Bayesian learning implies that unemployed workers do not know their search productivity type with certainty. As a consequence, they do not know their objective job-arrival rate (3). They therefore need to work with a subjective probability $p_{k}(s)$ that they are of the highproductivity type. The latter leads to a subjectively perceived contact rate

$$
\mu_{k}\left(s, p_{k}(s)\right)=\eta_{k}(s) \psi(s)\left[\phi_{k}(s) \theta_{k}\right]^{\alpha},
$$

\footnotetext{
${ }^{9}$ We introduce Bayesian learning about one's own job-search productivity to account for downward duration dependence in individual exit rates from unemployment at longer durations. Downward duration dependence in individual exit rates complements unobserved heterogeneity with respect to search productivity at the first stage of estimation to better match the falling aggregate exit rate from unemployment (see Launov and Wälde, 2013, for more discussion). If one believes that there is strong evidence of the absence of true individual duration dependence in certain economies, Bayesian learning could be removed from the model. Only unobserved heterogeneity would remain. Modelling learning with the same prior belief $p_{k}(0)$ at each new unemployment spell is a simplification that allows avoiding conditioning on the entire history of past unemployment. While we use learning, there are also alternative theoretical mechanisms to generate negative duration dependence, e.g. stigma (Lockwood, 1991) or firms' ranking of applicants by unemployment duration (Blanchard and Diamond, 1994; Fernandez-Blanco and Preugschat, 2015).

${ }^{10}$ The choice of concave utility and linear cost of search functions is suggested by the standard identification result in empirical job search models, which tells that from duration and benefit data one can identify either concave utility and linear cost of search or linear utility and convex cost of search, but not both simultaneously. As our theoretical model is designed to be structurally estimable, the choice of (2) reflects this implicit identification assumption. Sensitivity analysis (see Section 4.4) shows that such choice of functional forms is not restrictive.

${ }^{11}$ If we derived the aggregate matching function implied by this job-arrival rate, we would see that an individual's search productivity and the effectiveness of the PEA affect total factor productivity of the matching function in a constant returns fashion. Individual effort and tightness, however, are subject to decreasing returns (at the same power $\alpha$ ) as they are arguments of the matching function. This is the standard specification, see e.g. Pissarides (2000, ch. 5) for the case of effort and advertising.
} 
where $\eta_{k}(s)=\left(1-p_{k}(s)\right) \eta_{0, k}+p_{k}(s) \eta_{1, k}$ is the expected search productivity parameter of the contact rate computed on the individual's subjective belief $p_{k}(s)$. Upon successful contact with a firm, unemployed workers get a job that pays the net wage $w_{k}$.

Let $V_{k}(\psi(s), b(s), s)$ denote the value of unemployment at unemployment duration $s$ in skill group $k$ given the current state of the institutions: the PEA's duration-contingent effectiveness $\psi(s)$ and unemployment benefit $b(s)$. Furthermore, let $V\left(w_{k}\right)$ denote the value of a job at wage $w_{k}$. Unemployed workers choose search effort $\phi_{k}(s)$ to maximize their value of unemployment given their subjective probability of being a high-productive searcher. The Bellman equation for the value of unemployment reads

$$
\begin{aligned}
\rho V_{k}(\psi(s), b(s), s)=\max _{\phi_{k}(s)}\left\{v\left(b(s), \phi_{k}(s)\right)\right. & +\frac{d}{d s} V_{k}(\psi(s), b(s), s) \\
& \left.+\mu_{k}(s, p(s))\left[V\left(w_{k}\right)-V_{k}(\psi(s), b(s), s)\right]\right\},
\end{aligned}
$$

where $\rho$ is the rate of time preference. The first component under the max-operator shows the instantaneous utility of unemployment net of search costs. The second component is the deterministic change in the value of unemployment due to anticipation of the expiration of entitlement to UI and due to changes in the subjective probability of being high-productive in search. The last component is the expected gain from the transition to employment.

Once employed, individuals of skill type $k$ receive the net wage $w_{k}$ and do not search for jobs anymore, enjoying the utility $v\left(w_{k}\right)=\frac{1}{1-\sigma}\left[w_{k}^{1-\sigma}-1\right]$. The worker-firm match is destroyed at the exogenous rate $\lambda_{k}$. Whenever losing the job, an individual starts the new unemployment spell with a restored full entitlement to UI benefits. Consequently, the Bellman equation for the value of employment reads

$$
\rho V\left(w_{k}\right)=v\left(w_{k}\right)+\lambda_{k}\left[V_{k}(\psi(0), b(0), 0)-V\left(w_{k}\right)\right] .
$$

The first component on the right hand side shows the instantaneous utility of employment and the second component reflects the capital loss due to job destruction.

- Firms

A worker-firm pair on the skill market $k$ produces output $A_{k}$. Firms pay the gross wage $w_{k}^{\text {gross }}=w_{k} /(1-\kappa)$, where $\kappa$ is the tax rate to finance unemployment benefits. Let $J\left(w_{k} /(1-\kappa)\right)$ denote the value of a producing firm and let $J_{0 k}$ denote the value of the vacant firm on the corresponding skill market. Then the value of the producing firm solves

$$
\rho J\left(\frac{w_{k}}{1-\kappa}\right)=A_{k}-\frac{w_{k}}{1-\kappa}-\lambda_{k}\left[J\left(\frac{w_{k}}{1-\kappa}\right)-J_{0 k}\right] .
$$

The term $A_{k}-w_{k} /(1-\kappa)$ on the right hand side of this Bellman equation shows the instantaneous profit. The remaining term illustrates the expected capital loss of the firm due to job destruction.

Vacant firms incur flow cost $\gamma_{k}$ of advertising the vacancy. Vacancies meet unemployed workers at rate $\bar{\mu}_{k} / \theta_{k}$, where $\bar{\mu}_{k}$ is the expected job finding rate of skill group $k$. Adding up the averages over types $\chi$, weighted by the respective type sizes, $\bar{\mu}_{k}$ is given by

$$
\bar{\mu}_{k}=\pi^{\chi} \int_{0}^{\infty} \mu_{k}(s, 1) f_{k}(s, 1) d s+\left(1-\pi^{\chi}\right) \int_{0}^{\infty} \mu_{k}(s, 0) f_{k}(s, 0) d s,
$$


where $f_{k}(s, \chi)$ is the equilibrium probability density of unemployment duration of the workers with skill level $k$ and search productivity $\chi$. This density can be written in terms of the hazard rate $\mu_{k}(s, \chi)$ from $(3)$ as $f_{k}(s, \chi)=\mu_{k}(s, \chi) e^{-\int_{0}^{s} \mu_{k}(y, \chi) d y}$.

We assume free entry into any of the $k$ markets which drives the value of a vacant job down to zero, $J_{0 k}=0$. This reduces the Bellman equation for the value of the vacant firm to $\gamma_{k}=\theta_{k}^{-1} \bar{\mu}_{k} J\left(w_{k}\right)$, where the right-hand side captures the expected value of future production. Combined with $(7)$ this leads to a job creation curve in $\left(\theta_{k}, w_{k}\right)$-space.

- Wages

Wages are set according to collective bargaining, where we explicitly account for riskaversion as well as for the fact that UI and UA benefits are proportional to the previous net wage prior to the benefit reform. The assumption of collective bargaining is made for empirical realism in Germany and for tractability. It allows us to abstract from timedependent outside options and implied within-group distributions of wages. For the same reason, we assume that entitlement to UI payments is always given by $\bar{s}$ once a worker loses the job. Denoting by $\beta$ the bargaining power of the worker side, the wage equation reads ${ }^{12}$

$$
\begin{aligned}
& (1-\beta) v\left(w_{k}\right)+\beta m_{w_{k}} w_{k} \\
& =(1-\beta) v\left(b_{U I, k}, \phi_{k}(0)\right)+\beta(1-\kappa) m_{w_{k}}\left[A_{k}+\gamma_{k} \theta_{k} \frac{\mu_{k}(0, p(0))}{\bar{\mu}_{k}}\right],
\end{aligned}
$$

where

$$
m_{w_{k}}=v_{w}\left(w_{k}\right)+\frac{\lambda_{k}}{\rho+\mu_{k}(0, p(0))} v_{w}\left(b_{U I, k}, \phi_{k}(0)\right)
$$

is the generalized marginal effect of $w_{k}$ on instantaneous utility. The generalization of the marginal effect obtains because a marginal increase in $w_{k}$ increases utility not only by the slope of the utility function at $w_{k}$ but also by the slope of the utility function at the future unemployment income $b_{U I, k}$ since the latter is a function of the current wage. If benefits were independent of wages, $v_{w}\left(b_{U I, k}, \cdot\right)=0$, and individuals were risk-neutral, $v_{w}\left(w_{k}\right)=1$, the right hand side of (9) would reduce to the wage as in the textbook Pissarides model.

The right hand side of (9) shows the contribution of utility from benefits when just having lost the job and the tax-rate weighted effect of the production side. The effect of more vacancies per unemployed worker, i.e. of higher $\theta_{k}$, is weighted by the arrival rate right after the job loss divided by the average arrival rate. This latter generalization is due to the non-stationary nature of the search environment.

- The government

The government finances unemployment benefits through labour tax revenues. Let $N_{k}$ denote the fixed measure of the labour force of skill $k$. Let $L_{k}$ denote the endogenous measure of employment of skill $k$, such that $U_{k} \equiv N_{k}-L_{k}$ measures unemployment. Then,

\footnotetext{
${ }^{12}$ See the web appendix for a derivation and Launov and Wälde (2013) for more discussion.
} 
the measures of UI and UA recipients are given by

$$
\begin{aligned}
U_{k}^{U I} & =\left(N_{k}-L_{k}\right)\left[\pi^{\chi} \int_{0}^{\bar{s}} f_{k}(s, 1) d s+\left(1-\pi^{\chi}\right) \int_{0}^{\bar{s}} f_{k}(s, 0) d s\right], \\
U_{k}^{U A} & =\left(N_{k}-L_{k}\right)\left[\pi^{\chi} \int_{\bar{s}}^{\infty} f_{k}(s, 1) d s+\left(1-\pi^{\chi}\right) \int_{\bar{s}}^{\infty} f_{k}(s, 0) d s\right] .
\end{aligned}
$$

The integrals in (11) reflect the share of individuals within the UI and UA range for specific types $\chi$. Multiplying the $\pi^{\chi}$-weighted overall share of, say, short-term unemployed workers in (11a) by the measure of unemployed workers gives the measure $U_{k}^{U I}$ of short-term unemployed workers of skill $k$. The interpretation of $(11 \mathrm{~b})$ is in analogy.

A measure $\sum_{k=1}^{K} U_{k}^{U I}$ of short-term unemployed workers receives $U I$ benefits and the measure $\sum_{k=1}^{K} U_{k}^{U A}$ receives $U A$ benefits. These are paid by the labour tax levied on the gross wage $w_{k} /(1-\kappa)$ of the employed workforce $L_{k}$. Consequently, the budget of the government is given by

$$
b_{U I} \sum_{k=1}^{K} U_{k}^{U I}+b_{U A} \sum_{k=1}^{K} U_{k}^{U A}=\sum_{k=1}^{K} \kappa \frac{w_{k}}{1-\kappa} L_{k} .
$$

The government chooses the tax rate $\kappa$ such that this budget is balanced at any time.

- Optimal search behaviour

Given our specification of the instantaneous utility function in (2) and the specification of the subjective arrival rate in (4), optimal effort of job-searchers is determined by the first-order condition to (5) that reads (see the web appendix)

$$
\phi_{k}(s)=\left\{\alpha \eta_{k}(s) \psi(s) \theta_{k}^{\alpha}\left[V\left(w_{k}\right)-V_{k}(\psi(s), b(s), s)\right]\right\}^{1 /(1-\alpha)} .
$$

Effort rises in the individual's subjective mean search productivity $\eta(s)$ and in effectiveness $\psi(s)$ of the PEA. It also rises in the search incentives resulting from the difference between the value of being employed and the value of being unemployed.

At the heart of each Bayesian learning process is the updating of subjective beliefs. Unemployed workers that do not find a job observe that they are still unemployed. This objective information is combined with their subjective belief to be a good searcher. The resulting dynamics of the belief $p_{k}(s)$ of being high-productive in search is given by (see web appendix)

$$
\frac{d}{d s} p_{k}(s)=-p_{k}(s)\left(1-p_{k}(s)\right)\left[\mu_{k}(s, 1)-\mu_{k}(s, 0)\right]<0 .
$$

As the job-arrival rate of a good searcher $\mu_{k}(s, 1)$ is always higher than the one for a bad searcher, $\mu_{k}(s, 0)$, this equation tells us that the belief $p_{k}(s)$ falls over time for any skill group $k$. Intuitively speaking, the longer the duration in unemployment, the harder it is for an individual to keep up the belief that she actually has good abilities in searching for and finding a job. 


\section{- Equilibrium unemployment}

Equilibrium in our model implies endogenous unemployment rates per skill group $k$, labour market tightness, wages and a tax rate, $\left\{u_{k}, \theta_{k}, w_{k}, \kappa\right\}_{k=1}^{K}$. The job creation curve from the free entry condition, the wage equation and the budget constraint of the government allow to fix $\theta_{k}, w_{k}$ and $\kappa$, where all elements are such that optimality condition for $\phi_{k}(s)$ is satisfied for any $s$ (see Launov and Wälde, 2013, for a precise equilibrium characterization). Determining the equilibrium unemployment rates in our model requires more elaboration given the time-dependent exit risk from unemployment.

Consider the following definitions. Let $t$ denote calendar time and let $\tau>t$ be the future. There are two states of nature, employment $(e)$ and unemployment $(u)$, and two indices $i$ and $j$ such that both $i \in\{e, u\}$ and $j \in\{e, u\}$. Let $s(t)$ be the duration in a given state of nature in $t$. Define by $P_{i j}^{k, \chi}(\tau, s(t))$ the probability of being in state $j$ at some future moment $\tau$ for an individual of skill-group $k$ and search type $\chi$ who is currently in state $i$ and whose duration in $i$ is $s(t)$. We can then express the probability of being unemployed at some $\tau$, given a current duration in unemployment of $s(t)$, as

$$
P_{u u}^{k, \chi}(\tau, s(t))=e^{\int_{t}^{\tau} \mu_{k}(s(y), \chi) d y}+\int_{t}^{\tau} e^{\int_{t}^{\nu} \mu_{k}(s(y), \chi) d y} \mu_{k}(s(\nu)) P_{e u}^{k, \chi}(\tau-\nu, 0) d \nu .
$$

The probability of being unemployed at some future moment $\tau$, given that an individual is currently employed with duration $s(t)$, is then given by

$$
P_{e u}^{k, \chi}(\tau, s(t))=\int_{t}^{\tau} e^{\lambda_{k}(\nu-t)} \lambda_{k} P_{u u}^{k, \chi}(\tau-\nu, 0) d \nu .
$$

Equation (15) says that to be unemployed in $\tau$ conditional on being currently unemployed with duration $s(t)$ one can either remain unemployed continuously from $t$ to $\tau$ or remain unemployed only up to any future moment $\nu$, find a job at $\nu$, which happens at rate $\mu_{k}(s(\nu), \chi)$, and later on be unemployed by $\tau$ again. The probability to be unemployed in $\tau$ again conditional on being employed in $v$ is given by $P_{e u}^{k, \chi}(\tau-\nu, 0)$. Equation (16) tells us that in order to be unemployed in $\tau$ conditional on being currently employed with duration $s(t)$ one can lose a job at any future moment $\nu$, which happens at rate $\lambda_{k}$, and later be unemployed by $\tau$ again, the probability of which is given by $P_{u u}^{k, \chi}(\tau-\nu, 0)$. Furthermore, since the job destruction rate is time invariant, $P_{e u}^{k, \chi}(\tau, s(t))$ is in fact independent of $s(t)$, so we can write $P_{e u}^{k, \chi}(\tau, s(t))=P_{e u}^{k, \chi}(\tau)$. Finally note that $P_{u u}^{k, \chi}(\tau, s(t))$ and $P_{e u}^{k, \chi}(\tau)$ are interdependent, so (15) and (16) represent a system of two integral equations for these two probabilities. ${ }^{13}$

Knowing $P_{u u}^{k, \chi}(\tau, s(t))$ and $P_{e u}^{k, \chi}(\tau)$, one can compute the expected number of unemployed workers of skill $k$ and type $\chi$ at any future moment $\tau$,

$$
E_{\tau}\left(N_{k, \chi}-L_{k, \chi}(\tau)\right)=\left(N_{k, \chi}-L_{k, \chi}(t)\right) \int_{0}^{\infty} P_{u u}^{k, \chi}(\tau, s(t)) d H_{k}(s(t), \chi)+L_{k, \chi}(t) P_{e u}^{k, \chi}(\tau),
$$

where $N_{k, \chi}$ is the size of the labour force and $L_{k, \chi}(t)$ is the size of employment of skill $k$ and type $\chi$ at $t$, and $H_{k}(s(t), \chi)$ is the corresponding cross-sectional distribution of unemployment duration at $t$. Dividing (17) by $N_{k, \chi}$ gives the expected skill-type unemployment rate

\footnotetext{
${ }^{13}$ See the web appendix for the implementation in matlab and for more background.
} 
at any future moment $\tau$. Denoting by $u_{k, \chi}$ the long-term unemployment rate of $k$ - $\chi$ workers and letting $\tau$ go to infinity one gets (see web appendix)

$$
u_{k, \chi}=\frac{P_{e u}^{k, \chi}}{P_{e u}^{k, \chi}+\left[1-\int_{0}^{\infty} P_{u u}^{k, \chi}(s) d F_{k}(s, \chi)\right]} .
$$

Probabilities $P_{u u}^{k, \chi}(s)$ and $P_{e u}^{k, \chi}$ in (18) are limits of (15) and (16) for $\tau \rightarrow \infty$ and $F_{k}(s, \chi)$ is the steady state distribution of unemployment duration $s$ of a skill-type group used as density e.g. in (8). ${ }^{14}$

Aggregation over types for each skill gives the skill-specific unemployment rate $u_{k}=$ $\pi^{\chi} u_{k, 1}+\left(1-\pi^{\chi}\right) u_{k, 0}$. Aggregation over all skills delivers the economy-wide unemployment rate $u=\Sigma_{k=1}^{K} \frac{N_{k}}{N} u_{k}$. Due to optimizing behaviour of individuals, $u$ is a function of our two institutions: the PEA and the benefit system. Exogenous changes to any of these institutions through the reform delivers endogenous reaction of equilibrium unemployment.

- Endogenous job separation

Our model misses an endogenous job separation mechanism as in Mortensen and Pissarides (1994). We believe that such an extension would be interesting in some general sense, but it is less clear whether it is of importance for the specific question at hand. Generally speaking, it has been stressed that endogenous job-separation rates are an important channel in understanding e.g. cross-country differences in unemployment rates (Jung and Kuhn, 2014). This is important for our setup as reservation productivities react to changes in matching efficiency. Adopting the argument by Jung and Kuhn (2014, p. 1318) for our case where the matching efficiency goes up, unemployment to employment transitions would rise. Unemployment would gain in attractiveness and the reservation productivity would go up. An idiosyncratic shock would be more likely to lead to a separation. The separation rate and outflows should therefore increase as Hartz III made the matching process more productive. Following this line of reasoning, an endogenous separation rate would increase equilibrium unemployment and the unemployment reduction effect predicted by our model would be weaker.

The reason why one should be cautions in believing that this mechanism would be directly relevant for understanding the effects of the Hartz reforms in 2003 on the unemployment rate lies in the fact that separation rates in Germany did not rise during this period. According to Elsby et al. (2013, fig. 3) or Krebs and Scheffel (2013, fig. 10), separation rates as of 2003 are basically constant and as of 2005 they clearly fall. An estimated version of the present model with an endogenous separation rate would therefore probably predict only a mild dampening of the unemployment reduction effect, if at all. It would be highly interesting to confirm these conjectures in future research.

\footnotetext{
${ }^{14}$ Interestingly (and necessarily), the standard textbook expression $u=\lambda /(\lambda+\mu)$, suppressing dependence on $k$ and $\chi$, is a special case of our setup. When the job-finding rate is constant the corresponding probabilities become $P_{e u}=\lambda /(\lambda+\mu)$ and $P_{u u}=\lambda /(\lambda+\mu)$, delivering the result.
} 


\subsection{The intertemporal unemployment paradox}

We now analyze the effect of a rising effectiveness of the PEA. As a starting point, consider a steady state that reflects the situation in Germany before any reform. It is instructive to first simulate the reform of a PEA where the increase in matching effectiveness of the agency is identical for short- and long-term unemployed, i.e. where $\psi(s)=\psi$. For this case, a rise of $\psi$ by $1 \%, 3 \%$ and $5 \%$ reduces the unemployment rate by $0.17,0.47$ and 0.75 percentage points. ${ }^{15}$ More generally, there is a monotone decreasing relationship between the effectiveness of the PEA on the one hand and the aggregate unemployment rate on the other, quite as expected.

The picture changes considerably when we allow for heterogeneous increases of the effectiveness of the PEA for short- and long-term unemployed workers. Our model displays an unemployment paradox: an increase in effectiveness of the agency can lead to an increase in the unemployment rate. To illustrate the mechanism most clearly, let $\psi(s)=\psi^{U I}=1$ when $0 \leq s \leq \bar{s}$ and $\psi(s)=\psi^{U A}$ when $s>\bar{s}$. We ask what is the effect of a change in $\psi^{U A}$ on total hirings and the aggregate unemployment rate. The answer is plotted in Figure 2 for $\psi^{U A}$ ranging between 0.8 and 1.4 .
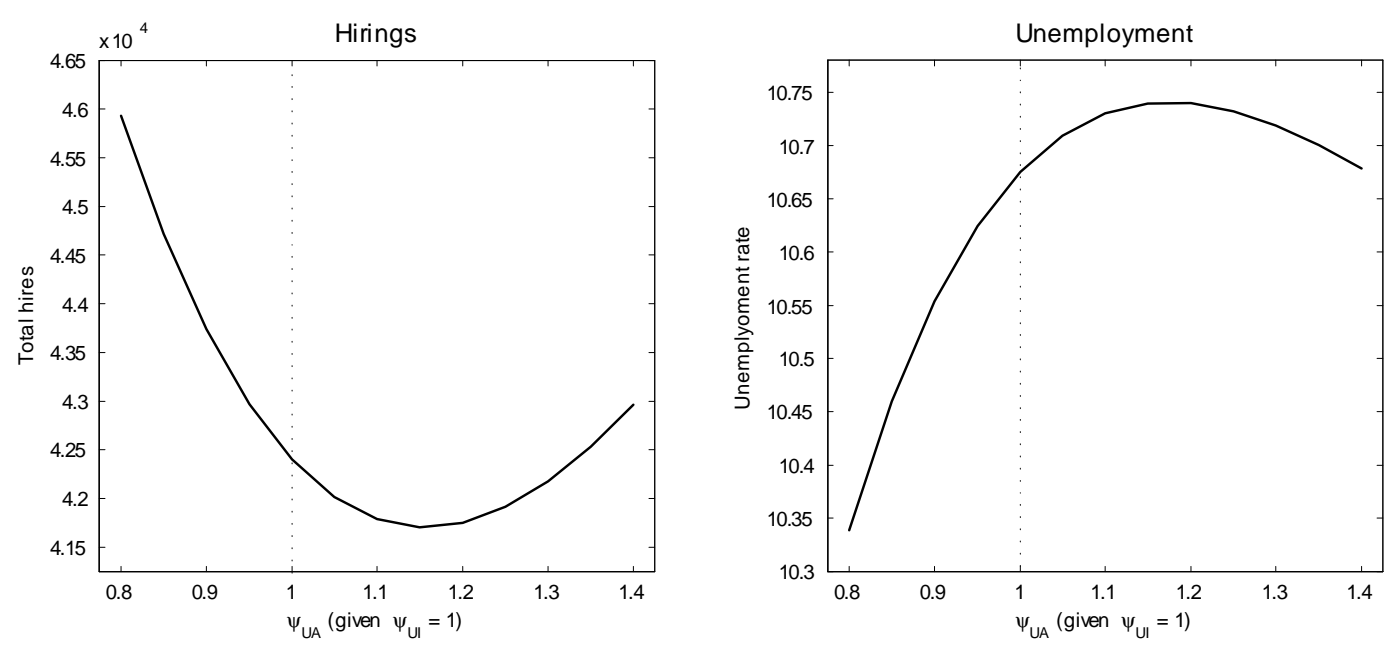

Figure 2 The intertemporal unemployment paradox: Changes in total hirings and the unemployment rate as a function of matching effectiveness for long-term unemployed workers

The left panel of this figure displays the aggregate number of matches and the right panel plots the aggregate equilibrium unemployment rate. This figure clearly shows the paradoxical effect: When effectiveness $\psi^{U A}$ of the public employment agency rises for longterm unemployed workers, keeping effectiveness $\psi^{U I}$ of short-term unemployed fixed, hirings initially go down and unemployment increases. When effectiveness $\psi^{U A}$ rises further, hirings rise again and unemployment falls.

This paradox emerges as there are two forces at work: A direct productivity effect for the long-term unemployed workers and an indirect disincentive effect for the short-term unemployed workers. The direct productivity effect per se is beneficial, i.e. higher productivity of

\footnotetext{
${ }^{15}$ Parameter values for this analysis are given by the values from our estimation further below. The matlab code is available on our web sites.
} 
PEA increases hirings and reduces the unemployment rate. The disincentive effect results from the anticipation by short-term unemployed workers that the productivity of PEA in matching them with vacant jobs and hence their exit rate will become higher once they turn long-term unemployed. As a consequence, they reduce their search effort and the exit rate of short-term unemployed workers goes down. Total hirings tend to go down as well and unemployment rises. As either of the two effects can dominate, the non-monotonicity arises. ${ }^{16}$

To back our intuition on the indirect incentive effect, consider the total number of matches $M$ which in our model amounts to

$$
M=\sum_{k=1}^{K} M_{k}=\sum_{k=1}^{K} \bar{\mu}_{k} U_{k}=\sum_{k=1}^{K}\left(\bar{\mu}_{k}^{U I}+\bar{\mu}_{k}^{U A}\right) U_{k},
$$

where $M_{k}$ is the number of matches at the $k$-th market and where we call

$$
\begin{aligned}
\bar{\mu}_{k}^{U I} & \equiv \pi^{\chi} \int_{0}^{\bar{s}} \mu_{k}(s, 1) f_{k}(s, 1) d s+\left(1-\pi^{\chi}\right) \int_{0}^{\bar{s}} \mu_{k}(s, 0) f_{k}(s, 0) d s, \\
\bar{\mu}_{k}^{U A} & \equiv \pi^{\chi} \int_{\bar{s}}^{\infty} \mu_{k}(s, 1) f_{k}(s, 1) d s+\left(1-\pi^{\chi}\right) \int_{\bar{s}}^{\infty} \mu_{k}(s, 0) f_{k}(s, 0) d s,
\end{aligned}
$$

the short-term and long-term exit rates, respectively. These exit rates illustrate averages for the intervals up to $\bar{s}$ and beyond. ${ }^{17}$ The right-hand side of (19) implies that matches change when (i) the number of unemployed changes and (ii) the exit rates $\bar{\mu}_{k}^{U I}$ and $\bar{\mu}_{k}^{U A}$ change.

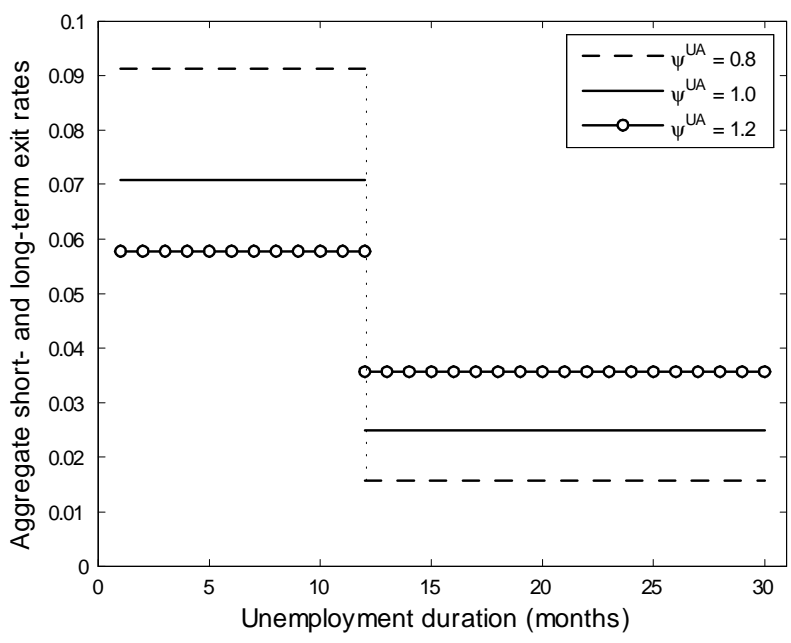

Figure 3 Understanding the intertemporal unemployment paradox: Aggregate short-term and long-term exit rates as a function of matching effectiveness for long-term unemployed workers

\footnotetext{
${ }^{16}$ Note that Bayesian learning and the implied falling exit rates from unemployment do not play a qualitative role in the unemployment paradox. The paradox would occur also in the absence of Bayesian learning. Similarily, this finding is also robust to allowing for endogenous separation rates.

${ }^{17}$ Despite the identical structure as in (8), $\bar{\mu}_{k}^{U I}$ is not the average exit rate of short-term unemployed workers as the density is defined from 0 to infinity but the integral covers the range from 0 to $\bar{s}$ only. The same applies to $\bar{\mu}_{k}^{U A}$.
} 
To confirm our intuition, Figure 3 fixes $\psi^{U I}=1$ as in Figure 2 and depicts the aggregate exit rates, where aggregation is over $k$. It considers three different cases: $\psi^{U A}=$ $\{0,8,1.0,1.2\}$. The plain solid line is the agency that is equally effective for short- and longterm unemployed $\left(\psi^{U I}=\psi^{U A}=1\right)$. This is the benchmark. For the agency that is relatively more effective in the long term $\left(\psi^{U A}=1.2\right)$, the exit rate for long-term unemployed workers goes up, but the exit rate for short-term unemployed workers falls. This is exactly the effort reducing effect of anticipating higher PEA effectiveness in the future. The reverse would hold if the agency became relatively less effective in the long term $\left(\psi^{U A}=0.8\right)$ : The exit rate rises for UI recipients and falls for UA recipients. Knowing about a worse quality of the PEA in the future induces short-term unemployed workers to try even harder and find a job before entitlement to UI expires.

We now look at our phenomenon from a slightly different perspective. The incentive to search for a job before the expiration of entitlement to UI should decrease more strongly, the more productive the unit of the agency to which the unemployed worker is soon transferred. ${ }^{18}$ To confirm this, we consider search effort of an unemployed worker at two different moments of unemployment duration, one right after entry to unemployment and another right before expiration of entitlement to UI benefit. The higher the productivity of the PEA in matching long-term unemployed is, the larger should be the discrepancy between search effort measures at these two moments.

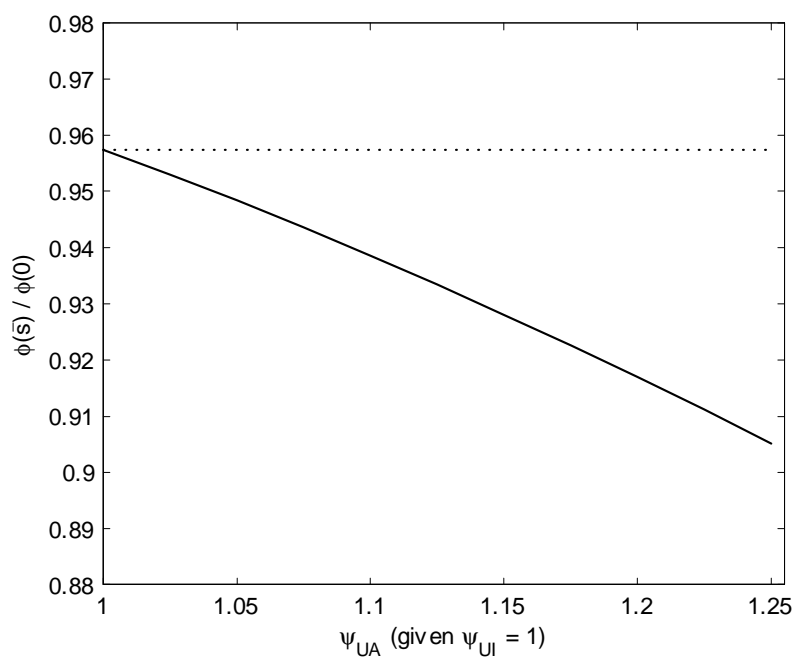

Figure 4 Understanding the intertemporal unemployment paradox: Ratio of aggregate search efforts as a function of matching effectiveness for long-term unemployed workers

Figure 4 illustrates the aggregate search effort at the end of the entitlement period relative to aggregate search effort at the beginning of the entitlement period, $\phi(\bar{s}) / \phi(0)$, where aggregation is over $k$. The ratio of the aggregate search efforts (solid line) is plotted as a function of PEA productivity for long-term unemployed while productivity for short-term unemployed is normalized to unity. The dotted line in Figure 4 marks the case of the constant

\footnotetext{
${ }^{18}$ We are grateful to a referee for having suggested this way of looking at our finding.
} 
productivity of the agency regardless of duration $\left(\psi_{U I}=\psi_{U A}=1\right)$. We see that the higher is $\psi_{U A}$, the stronger is the distortion of search effort at the end of entitlement and hence the bigger is the fall of the ratio of search efforts. This once again confirms our intuition on the disincentive effect.

Concluding the present discussion, it seems to be a purely empirical question whether heterogeneous increases in matching effectiveness of a PEA throughout the duration of unemployment will be such that unemployment actually falls. It cannot be taken for granted that any increase of productivities of an agency leads to a reduction of the unemployment rate.

\section{The impact of the reform of the agency}

\subsection{Econometric specification}

- Data and estimation procedure

We estimate the effect of the reform of PEA using the following two-stage econometric procedure. At the first stage we estimate all parameters of the pre-reform steady state, in which effectiveness parameters of the PEA are normalized to unity. Structural parameters of the pre-reform steady state are estimated using maximum likelihood from survey data on individual employment histories. The data source is the German Socio-Economic Panel (see Appendix A.2 for a brief description). The entire structural econometric model for the pre-reform steady state of Section 3.1, together with discussion of identification and estimation results, is described in Launov and Wälde (2013). Since the first stage of the econometric analysis of the present paper and the entire econometric analysis of Launov and Wälde (2013) are identical, we borrow their estimation results for this paper and proceed to the second stage.

At the second stage, given the estimates of the structural parameters of the pre-reform steady state, we estimate the increase in matching effectiveness of the agency for short- and long-term unemployed workers, i.e. $\psi^{U I}$ and $\psi^{U A}$. The impact of the reform is estimated using indirect inference (see Gourieroux et al., 1993, for indirect inference, and Postel-Vinay and Turon, 2010, for a similar two-step approach). The idea of indirect inference amounts to defining an auxiliary reduced-form econometric model and estimating this auxiliary model once on the real data and once on the synthetic data drawn from the structural model given the particular choice of the unknown structural parameters. Adjusting parameters of the structural model in such a way that the relevant moments of the auxiliary model estimated on the actual data and on the synthetic data coincide delivers indirect estimates of the structural parameters.

The real data we use are the regional data on the stocks of matches, unemployment and vacancies provided by the Federal Employment Agency (see Appendix A.2 for a brief description). ${ }^{19}$ The cross-sectional unit is a regional labour market, at the level of a federal land, and the time unit is year. In the benchmark specification we analyze the period from

\footnotetext{
${ }^{19}$ The same data set was used for estimation in Klinger and Rothe (2012). We are grateful to Sabine Klinger and Thomas Rothe for making these data available to us.
} 
2000 to 2008, cutting the sample in 2008 to eliminate the effects of the Great Recession on the German labour market. After that we perform a sensitivity analysis adding year 2009 to check for robustness to the recession. ${ }^{20}$ The synthetic data consist of the stocks of matches, unemployment and vacancies implied by the structural model of Section 3.1 given a particular choice of $\psi^{U I}$ and $\psi^{U A}$. The cross-sectional unit is a 'skill' $\times$ 'regional' labour market and the time unit is year. The benchmark estimation likewise relates to the period from 2000 to 2008, and the sensitivity analysis adds the year of the Great Recession. Both real and synthetic data allow making an explicit distinction between matches for short-term and long-term unemployed workers.

When specifying an auxiliary reduced-form model, even though parameters of such a model need not necessarily have a clear economic interpretation, auxiliary model needs to satisfy two requirements. First, it needs to resemble the structural model as close as possible (see Bagger et al., 2014). Second, it must have as close a fit to real data as possible. Since our application considers the impact of the increased effectiveness of PEA on the number of matches, the most natural choice for an auxiliary model is an empirical matching function. ${ }^{21}$

We consider a classical empirical matching function equation à la Blanchard and Diamond (1989) with matches on the left hand side and stocks of vacancies and unemployment, time trend and further explanatory variables on the right hand side. For the real data on shortterm matches we write

$$
\begin{aligned}
& \ln M_{i t}^{\text {short }}=\beta_{0, s}+\beta_{1, s} \ln U_{i t}^{\text {short }}+\beta_{2, s} \ln V_{i t}+\beta_{3, s} t+\beta_{4, s} t^{2}+\beta_{5, s} d^{2005} \\
& +\delta_{s}^{I \& I I} \text { HartzI\&II }+\delta_{s}^{I I I} H a r t z I I I+\delta_{s}^{I V} \operatorname{HartzIV}+\iota_{i, s}+\epsilon_{i t, s}, \\
& \epsilon_{i t, s}=\varphi_{s} \epsilon_{i t, s}+\varepsilon_{i t, s}, \quad \varepsilon_{i t, s} \sim N\left(0, \sigma_{\varepsilon, s}^{2}\right), \quad \iota_{i, s} \sim N\left(0, \sigma_{\iota, s}^{2}\right),
\end{aligned}
$$

where $\iota_{i, s}$ stands for market-specific effects on the matches of short-term unemployed workers and $\epsilon_{i t, s}$ follows a first-order autoregressive process with coefficient $\varphi_{s}$. Similarly, for the real data on long-term matches we write

$$
\begin{aligned}
& \ln M_{i t}^{\text {long }}=\beta_{0, l}+\beta_{1, l} \ln U_{i t}^{\text {long }}+\beta_{2, l} \ln V_{i t}+\beta_{3, l} t+\beta_{4, l} t^{2}+\beta_{5, l} d^{2005}+\beta_{6, l} d^{2006} \\
& +\delta_{l}^{I \& I I} H a r t z I \& I I+\delta_{l}^{I I I} H a r t z I I I+\delta_{l}^{I V} H a r t z I V+\iota_{i, l}+\epsilon_{i t, l}, \\
& \epsilon_{i t, l}=\varphi_{l} \epsilon_{i t, l}+\varepsilon_{i t, l}, \quad \varepsilon_{i t, l} \sim N\left(0, \sigma_{\varepsilon, l}^{2}\right), \quad \iota_{i, l} \sim N\left(0, \sigma_{\iota, l}^{2}\right),
\end{aligned}
$$

where $\iota_{i, l}$ and $\epsilon_{i t, l}$ have the same interpretation as $\iota_{i, s}$ and $\epsilon_{i t, s}$ above.

The variable of our primary interest in (21) and (22) is HartzIII. This is a dummy variable that captures the impact of the reform of the PEA on matches. It takes the value of "0" before 2004 and "1" from 2004 onwards. This variable is the only explanatory variable in

\footnotetext{
${ }^{20}$ Officially Germany entered the recession in the 2nd quarter of 2008, and the recession lasted for one year. Despite that, German unemployment rate kept falling until the end of 2008. During the first three quarters of 2009 it has been on the rise and then it started falling again reaching the pre-recession level by the end of 2009 (see e.g. OECD, 2014). Therefore we rather choose year 2009 to relfect the influence of the Great Recession.

${ }^{21}$ We are not the first to make such a choice. Empirical matching function has been already used by e.g. Fahr and Sunde (2009) and Klinger and Rothe (2012) to analyze the effect of different packages of the Hartz reform in Germany on the number of matches. For a review of related applications of empirical matching functions see Petrongolo and Pissarides (2001).
} 
(21) and (22) pertinent to the reform of the PEA. The rest of the variables control for changes in economic environment unrelated to time trend and the PEA reorganization. HartzI\&II controls for the effect of the first two packages of the reform, taking the value of " 0 " before 2003 and "1" thereafter. HartzIV does the same for the effect of the last package of the reform with a value of "0" before 2005 and "1" afterwards. Finally, two dummy variables, $d^{2005}$ and $d^{2006}$ account for structural breaks in the statistics on unemployed workers. Dummy $d^{2005}$ (= 1 in 2005) reflects the fact that in 2005 former recipients of social assistance benefits had to register as unemployed; dummy $d^{2006}(=1$ in 2006) accounts for introduction of new statistics in municipalities that were taking care of long-term unemployed on their own (see Klinger and Rothe, 2012, for more details).

One potential point of concern for identification of the effect of the PEA reform on dynamics of matches in auxiliary regressions on the real data is the spacing between introduction of each new package of the Hartz reform. The time span between any two adjacent packages is one year. While the reforms under Hartz I and II and the Hartz IV reform have arguably a relatively short transition time to the new equilibrium, the transition after the reform of the PEA takes longer. Thus the estimate for the HartzIII dummy will be to some extent confounded by the short-term effect of the reform. Depending on whether the immediate impact of the reform is above or below its long-term value, this estimate may drift in both directions. Nevertheless, given very strong effects previously found in the literature ${ }^{22}$ we are confident that the long-term impact of the PEA reform survives in any case.

Once estimation of (21)-(22) with the real data is completed we estimate $\psi^{U I}$ and $\psi^{U A}$ by matching estimates of $\delta_{s}^{I I I}$ and $\delta_{l}^{I I I}$ from the regression on the real data with estimates of $\delta_{s}^{I I I}$ and $\delta_{l}^{I I I}$ from the regression on the synthetic data given a particular choice of $\psi^{U I}$ and $\psi^{U A}$. The synthetic sample captures growth over the period of 2000-2008/09 by conditioning on changes in labour productivity taken from OECD (2014). A bias from other packages of the reform as well as from structural breaks in unemployment statistics is eliminated from the synthetic sample simply by not simulating these packages and breaks. With two parameters to match and two parameters to estimate the identification is exact. Estimates of $\psi^{U I}$ and $\psi^{U A}$ are obtained by application of the equally weighted minimum distance estimator. Low dimensionality of the estimation problem allows using grid search.

- Simulation of the reform

Once estimates of $\psi^{U I}$ and $\psi^{U A}$ are available, the impact of the PEA reform (Hartz III) is measured by the difference in equilibrium unemployment rates before and after the reform, net of labour productivity growth. In addition, we want to know how the impact of the improved PEA compares to the impact of the reform of the benefit system, which followed thereafter. To simulate the effect of the benefit reform (Hartz IV), we do not need any additional estimation. Instead we look at each of the 'skill' $\times$ 'regional' markets. We consider the observed distribution of UA payments immediately before the reform and the observed distribution of ALG II payments immediately after the reform. The difference in mean values of these distributions marks skill-specific changes in the benefit level due to introduction of ALG II. Skill-specific changes in the duration of entitlement to UI are treated in the same way. The impact of the entire benefit reform is measured by the difference in

\footnotetext{
${ }^{22}$ See Fahr and Sunde (2009) and Klinger and Rothe (2012).
} 
the equilibrium unemployment rates before and after the benefit and entitlement cut, net of labour productivity growth.

Lastly, one might be tempted to suggest that using the very same indirect inference approach one could estimate the influence of Hartz I and II left out in the present paper. While not unthinkable, the essential difficulty with this suggestion is that Hartz I and II include a whole set of measures which affect individual behaviour in diverse ways. If one attempts to introduce at least the most important measures into the structural model, one would immediately run into an identification problem, as equations (21) and (22) each contain only one coefficient $\delta_{j}^{I \& I I}$ to identify more than one structural parameter, $j=s, l$. Extending the set of auxiliary regressions to insure identification, and of course extending the theoretical model for multitude of policies under Hartz I and II, is a project in itself.

\subsection{Estimation results}

Let us now consider the estimation results for all the structural parameters. Characteristics of the pre-reform steady state and estimates of the structural parameters from the first stage are reported in Table A.1 of Appendix A.2. Estimates of the effectiveness parameters of the agency from the second stage are reported in Table 1 below.

The left block of Table 1 shows estimates of the parameters of interest from the auxiliary regressions $\left(\delta_{\text {short }}^{I I I}\right.$ and $\left.\delta_{\text {long }}^{I I I}\right)$. The right block of this table shows estimates of the corresponding structural parameters. Details on estimation of auxiliary regressions are relegated to Appendix A.3, with an entire set of estimation results for these regressions reported in Table A.3. Here we just note that a quadratic time trend is supported only in the equation for short-term unemployed, that the time trend is linear for long-term unemployed, and that auxiliary regressions have a very good fit to the real data.

\begin{tabular}{|c|c|c|c|c|}
\hline \multicolumn{3}{|c|}{ Auxiliary regressions } & & \multirow{2}{*}{$\begin{array}{l}\text { Structural } \\
\text { parameters }\end{array}$} \\
\hline & real data & synthetic data & & \\
\hline $\begin{array}{l}\delta_{\text {short }}^{I I I} \\
\delta_{\text {long }}^{I I I}\end{array}$ & $\begin{array}{l}0.0684(0.0191) \\
0.0601(0.0333)\end{array}$ & $\begin{array}{l}0.0685(0.0088)[-0.0042] \\
0.0601(0.0073)[-0.0001]\end{array}$ & $\begin{array}{c}\psi^{U I} \\
\psi^{U A}\end{array}$ & $\begin{array}{l}1.076(0.020) \\
1.230(0.024)\end{array}$ \\
\hline
\end{tabular}

Standard errors in parenthesis; t-statistic for a test of pairwise equality of estimated coefficients on real and synthetic data in square brackets. Standard errors for structural parameters disregard the first stage.

Table 1 Impact of the reform on matching effectiveness of the agency

The left block of Table 1 underlines exceptionally high accuracy of our estimation procedure. First, the distance between reduced-form coefficients estimated from the real data and synthetic data is negligible both for short-term and long-term matches. Second, $t$-statistics in the test of pairwise equality of the coefficients of interest estimated from the real and synthetic data have extremely small values in both regressions. This adds confidence to the accuracy of our indirect estimates of $\psi^{U I}$ and $\psi^{U A}$, taking the auxiliary model as given. 
Later on we also perform sensitivity analysis with respect to specification of the auxiliary model.

Indirect estimates of the structural parameters of the PEA effectiveness, reported in the right block of Table 1, reveal an interesting result. They show that the effectiveness of the agency in matching short-term unemployed workers with vacant jobs has increased by $7.6 \%$ due to the reform. Effectiveness of the agency in matching long-term unemployed has increased by as much as $23.0 \%$. Both increases are significant, emphasizing that the reform of the Federal Employment Agency in Germany was a success in terms of reducing coordination frictions between unemployed workers and vacant jobs. Furthermore we can see that the reform has improved the situation for long-term unemployed workers significantly more.

Such results on $\psi^{U I}$ and $\psi^{U A}$ give rise for two intriguing questions. First, what is the impact of the increase in matching effectiveness by $7.6 \%$ for short-term and by $23.0 \%$ for long-term unemployed workers on the equilibrium unemployment rate? Second, in view of discussion of Section 3.2, how big is the disincentive effect of this unequal increase in the matching effectiveness for short- and long-term unemployed workers? We answer these questions next.

\subsection{Evaluation of the reform}

- Equilibrium impact of the reform

Table 2 summarizes the computed fall of the equilibrium unemployment due to the improvement of the PEA and the subsequent reduction of benefit generosity. Already the first row of this table shows one of the key results of the present analysis. We see that the $7.6 \%$ increase in matching effectiveness of the agency for short-term unemployed and $23.0 \%$ increase in matching effectiveness for long-term unemployed lead to a 0.88 percentage point reduction of the unemployment rate. This reduction amounts to $22.51 \%$ of the observed decline in unemployment in Germany between the implementation of the last package of the Hartz reform and the beginning of the Great Recession. It establishes that the reform of the PEA in Germany holds a substantial stake in the way unemployment has been managed before the world financial crises erupted.

Considering the public attention devoted to each package of the Hartz reform at the time, this result comes somewhat as a surprise, since the reform of the Federal Employment Agency was the package least publicized of all four. Just in contrast, it was the UA benefit cut and the reduction of entitlement duration to UI that stirred media and public debates most. Our next result shows what is the actual impact of the benefit reform and what is the contribution of the preceding reform of the PEA to the strength of this impact. The benefit reform is evaluated using the reduction of UA benefits and duration of entitlement to UI reported in Table A.2 of Appendix A.2.

The equilibrium effect of the benefit reform can be computed in two ways. First, we can evaluate this effect as if there was no reform of the PEA before. Line (2) of Table 2 tells us that in such a case a reduction of benefit generosity under arrangements of Hartz IV would lead to just 0.08 percentage point fall in the equilibrium unemployment rate. This amounts to very modest $2.1 \%$ of the observed decline in unemployment, suggesting that the undertaken 
reduction of benefit generosity is by far not sufficient to influence the unemployment rate in a tangible way. Second, we can compute the impact of the reform of the PEA and benefits sequentially and see what is the effect of the benefit reform given that improvement of the PEA has taken place prior to benefit and entitlement cuts. Line (3) of Table 2 displays the joint impact of both reform packages, showing a 1.1 percentage point reduction of the equilibrium unemployment rate as a consequence. It conveys that both packages explain $27.1 \%$ of the observed post-reform decline in unemployment. Taking the net effect of the benefit reform conditional on the reform of the PEA, which is done in line (4) of Table 2, we find that the benefit reform leads now to 0.18 percentage point reduction in the equilibrium unemployment rate. This more than doubles the unconditional effect and explains already $4.6 \%$ of the observed post-reform unemployment decline.

\begin{tabular}{|c|c|c|c|}
\hline & & $\begin{array}{l}\text { Unemploym } \\
\text { absolute (ppt) }\end{array}$ & $\begin{array}{l}\text { nt reduction } \\
\text { explained }\end{array}$ \\
\hline (1) & Hartz III & 0.88 & 22.51 \\
\hline (2) & Hartz IV & 0.08 & 2.05 \\
\hline (3) & Hartz III and IV & 1.06 & 27.11 \\
\hline (4) & Hartz IV given Hartz III ${ }^{\text {a) }}$ & 0.18 & 4.60 \\
\hline (5) & Interaction of Hartz III and Hartz IV ${ }^{\mathrm{b})}$ & 0.10 & 2.56 \\
\hline
\end{tabular}

a) Line (3) minus line (1) b) Line (4) minus line (2)

Table 2 Reduction of the unemployment rate explained by reforms

Thus we find that improvement of the PEA prior to benefit reform has actually amplified the effect of the benefit reform. This amplification takes place because considerable increase in matching effectiveness of the PEA for long-term unemployed pushes up the value of longterm unemployment. Consequently, elasticity of the exit rate out of unemployment with respect to UA benefits becomes higher, which leads to stronger reaction to one and the same benefit cut. The size of this amplification effect due to the reform of the agency is reported in line (5) of Table 2: 0.10 percentage points. ${ }^{23}$

Summarizing the above analysis we find that the reform of the Federal Employment Agency in Germany accounts for 0.88 percentage points (or 22.5\%) of the decline in the unemployment rate, whereas the subsequent reduction of benefit generosity adds only 0.18 percentage points (or 4.6\%) to this decline. Moreover, 0.10 of these 0.18 percentage points due to reduction of benefit generosity were indeed assisted by the preceding improvement of the PEA. This underlines that in a typical welfare state an improvement of effectiveness of state employment agencies may have a much stronger influence on unemployment than unemployment benefit cuts of acceptable size.

\footnotetext{
${ }^{23}$ This finding also adjusts upwards the earlier estimate of the effect of the benefit reform by Launov and Wälde (2013), who disregarded the reform of PEA. Their impact of the benefit reform was as in line (2) of Table 2 .
} 
- Quantifying the unemployment paradox

The last point we would like to make concerns the disincentive effect discussed in Section 3.2. First of all, line (1) in Table 2 suggests that the positive effectiveness effect is unambiguously stronger than the negative incentive effect, since the net influence of the reform reduces the unemployment rate. Yet, the Hartz III reform could have been designed in a more efficient way. Consider the alternative where the increase in matching effectiveness both for short- and long-term unemployed workers is at the level we find for short-term unemployed workers in the actual design (i.e. by $7.6 \%$ for both categories of unemployed). Obviously, this counterfactual alternative is less costly to the government than the actual one. Furthermore, it is free of the disincentive effect discussed in Section 3.2. We ask what would have been the reduction of the equilibrium unemployment rate if this counterfactual alternative would have been implemented in place of the actual design.

Our calculations show that an equal increase in matching effectiveness of the agency for short- and long term unemployed workers by $7.6 \%$ would have reduced the unemployment rate by as much as 1.09 percentage points. This exceeds the 0.88 percentage point reduction attained by the actual design by 0.21 . Thus, taking for granted that the actual design is more costly than the counterfactual one, we conclude that the actual design is clearly suboptimal. If the special emphasis on long-term unemployed workers had been avoided, the unemployment rate would have been reduced even more.

In an attempt to reduce the disincentive effect that arises from the heterogeneous treatment of short- and long-term unemployed workers at the PEA, one may wish to further reduce unemployment assistance. Indeed, if one takes the actual design and implements a 2.5 times stronger reduction in UA benefits, one arrives at the same impact as under the just suggested counterfactual design. However this does not eliminate the disincentive effect as such, because the very existence of preferential treatment of long-term unemployed by the agency will still distort search incentives.

\subsection{Sensitivity analysis}

How sensitive are our main results with respect to changes in several key parameters and parametric form assumptions of the model? First, we look into sensitivity of our indirect estimates of $\psi^{U I}$ and $\psi^{U A}$. As mentioned in Sections 4.1 and 4.2, this analysis has two dimensions: (i) sensitivity with respect to the specification of the auxiliary model, and (ii) sensitivity to the inclusion of the Great Recession. Next, we consider whether our policy simulation results are robust to the choice of (iii) predetermined parameters, such as the rate of time preference, and (iv) normalization of the cost of search function, as measured by the elasticity of unemployment duration with respect to entitlement to UI. We conclude by (v) inquiring how much evaluation results of Hartz IV depend on the assumption of how much UA benefits actually fell in Germany.

- Specification of the auxiliary model

Discussion on the estimation of auxiliary models (see Appendix A.3) concludes that the absence of the relevant critical values does not allow us to formally accept or reject first order 
autoregressive process in the error terms of both auxiliary regressions. All our results so far relied on auxiliary regressions with first order autoregressive process in the error terms, which we kept in order to be as general as possible. In what follows we consider an alternative specification where error terms in both auxiliary regressions are white noise. Results from this alternative specification are reported in Table 3, which should be read in the same way as Table 1.

Table 3 shows that regardless of the change in specification of the error term in auxiliary regressions, accuracy of indirect estimation remains very high. This is evident from the distance between estimates of $\delta_{\text {short }}^{I I I}$ as well as $\delta_{\text {long }}^{I I I}$ on the real and synthetic data; it is also supported by the corresponding values of t-statistics. We further see that the increase in matching effectiveness of the PEA is now equal to $6.1 \%$ for short-term and $22.9 \%$ for longterm unemployment workers. As before, both effects are statistically significant. However, the estimate of $\psi^{U I}$ falls a bit short of the previously estimated value of $7.6 \%$. The estimate of $\psi^{U A}$, to the contrary, remains insensitive to the change in specification of auxiliary regressions.

Even though we believe that first-order autoregressive processes in the error terms of both auxiliary equations are very likely to survive with more observations, we prefer to report our final results in terms of intervals. Thus, summing up, the reform of the PEA induces a 0.69 to 0.88 percentage point reduction of the equilibrium unemployment rate, which translates into $17.7 \%$ to $22.5 \%$ of the observed post-reform decline of unemployment in Germany. The subsequent benefit reform induces a 0.18 to 0.20 percentage point reduction of the equilibrium unemployment rate, explaining further $4.6 \%$ to $5.1 \%$ of the observed postreform unemployment decline. The dominant effect of the reform of the agency over the reform of the benefit system clearly survives this sensitivity analysis. ${ }^{24}$

\begin{tabular}{lcccc}
\hline \hline & \multicolumn{2}{c}{$\begin{array}{c}\text { Auxiliary regressions } \\
\text { synthetic data }\end{array}$} & & $\begin{array}{c}\text { Structural } \\
\text { parameters }\end{array}$ \\
\cline { 2 - 4 }$\delta_{\text {short }}^{\text {rII }}$ & $0.0279(0.0210)$ & $0.0280(0.0084)[-0.0009]$ & $\psi^{U I}$ & $1.061(0.003)$ \\
$\delta_{\text {long }}^{I I I}$ & $0.0417(0.0280)$ & $0.0418(0.0114)[-0.0029]$ & $\psi^{U A}$ & $1.229(0.003)$ \\
\hline
\end{tabular}

Standard errors in parenthesis; t-statistic for a test of pairwise equality of estimated coefficients on real and synthetic data in square brackets. Standard errors for structural parameters disregard the first stage.

Table 3 Sensitivity to specification: Impact of the reform on matching effectiveness of the agency

\footnotetext{
${ }^{24} \mathrm{~A}$ more outreaching analysis would combine a change in the specification with the application of a different estimator. For instance, Borowczyk-Martins et al. (2013) show that standard estimates of matching function elasticities are prone to simultaneity bias and suggest a procedure to alleviate the bias. It would certainly be interesting to use their approach and see if improved estimates of $\delta_{\text {short }}^{I I I}$ and $\delta_{\text {long }}^{I I I}$ in the actual and synthetic sample can influence the underlying $\psi^{U I}$ and $\psi^{U A}$. A further interesting avenue would add information on employed job-seekers.
} 
We ask whether the detected difference between estimates of $\psi^{U I}$ across different specifications of auxiliary regressions results in a big difference in the predicted decline of the unemployment rate. We repeat the entire equilibrium analysis, evaluating first the PEA reform and then the reform of the benefit system. Results of this analysis are reported in Table 4, which should be read in the same way as Table 2. We find that the reform of the PEA leads now to a 0.69 percentage point decline in the equilibrium unemployment rate, which explains $17.7 \%$ of the observed fall in unemployment. Comparing it to 0.88 percentage points (equivalently, 22.5\%) we see that the result is indeed slightly sensitive to the specification of auxiliary regressions. The impact of the subsequent benefit reform, however, remains virtually unaffected: 0.20 percentage points, or $5.1 \%$ (compared with 0.18 percentage points and $4.6 \%$ in Table 2 , respectively).

\begin{tabular}{|c|c|c|c|}
\hline & & \multicolumn{2}{|c|}{$\begin{array}{l}\text { Unemployment reduction } \\
\text { absolute (ppt) explained }(\%)\end{array}$} \\
\hline (1) & Hartz III & 0.69 & 17.65 \\
\hline (2) & Hartz IV & 0.08 & 2.05 \\
\hline (3) & Hartz III and IV & 0.89 & 22.76 \\
\hline (4) & Hartz IV given Hartz III ${ }^{\text {a) }}$ & 0.20 & 5.12 \\
\hline (5) & Interaction of Hartz III and Hartz IV ${ }^{\mathrm{b}}$ ) & 0.12 & 3.01 \\
\hline
\end{tabular}

a) Line (3) minus line (1) b) Line (4) minus line (2)

Table 4 Sensitivity to specification: Reduction of the unemployment rate explained by reforms

Lastly, implications of an alternative design that alleviates the disincentive effect remain virtually insensitive to the change in the specification of the auxiliary regressions. Considering the counterfactual design that increases effectiveness of the agency for short- and long-term unemployed workers equally by $6.1 \%$, instead of raising it to $22.9 \%$ for the longterm unemployed as in the actual design, we find that this counterfactual design leads to a 0.9 percentage point reduction of the unemployment rate. This again exceeds the reduction implied by the actual design by 0.21 percentage points, exactly as with the initial specification of the auxiliary regressions. Thus all of our conclusions on the suboptimality of the actual reform are confirmed.

- Adding the Great Recession

Consider now the inclusion of the recession. We extend our sample by one year and add to specification of auxiliary regressions in (21)-(22) a dummy variable $d^{2009}$ that accounts for recessionary drop in matches. Dummy $d^{2009}$ takes the value of " 1 " if year is 2009 , zero otherwise. Estimation accuracy in this part of the sensitivity analysis is a high as in all preceding parts, so to be brief we skip reporting the estimates of $\delta_{\text {short }}^{I I I}$ and $\delta_{\text {long }}^{I I I}$ (these can be found in Table A.3 of Appendix A.3). 


\begin{tabular}{|c|c|c|c|c|}
\hline & \multicolumn{2}{|c|}{$\varphi_{s} \neq 0, \varphi_{l} \neq 0$} & \multicolumn{2}{|c|}{$\varphi_{s}=0, \varphi_{l}=0$} \\
\hline \multirow{3}{*}{$\begin{array}{c}\psi^{U I} \\
\psi^{U A}\end{array}$} & 1.083 & $(0.003)$ & 1.081 & $(0.004)$ \\
\hline & 1.251 & $(0.026)$ & 1.271 & $(0.004)$ \\
\hline & $\begin{array}{l}\text { Unemplo } \\
\text { abs. }(p p\end{array}$ & $\begin{array}{l}\text { at reduction } \\
\text { expl. (\%) }\end{array}$ & \multicolumn{2}{|c|}{$\begin{array}{l}\text { Unemployment reduction } \\
\text { abs. (ppt) expl. (\%) }\end{array}$} \\
\hline Hartz III & 0.94 & 24.04 & 0.90 & 23.02 \\
\hline Hartz III and IV & 1.13 & 28.90 & 1.10 & 28.13 \\
\hline Hartz IV given Hartz III & 0.19 & 4.86 & 0.20 & 5.12 \\
\hline
\end{tabular}

Table 5 Sensitivity to adding the Great Recession

Table 5 summarizes all the results. Upper part of this table shows the estimated values of the structural parameters $\psi^{U I}$ and $\psi^{U A}$. Its lower part displays the predicted reduction of the unemployment rate due to the reforms of interest. We add the effect of the recession within two specifications. The benchmark specification (first two columns of Table 5) keeps autoregressive terms in the errors of both auxiliary regression equations. The restricted specification (last two columns of Table 5) removes autoregressive terms.

Comparing the results in Table 5 with the corresponding results of Tables 1 and 2 we see that our findings on the reform of the PEA are hardly sensitive to inclusion of the Great Recession. The predicted contribution of Hartz III to the reduction of the unemployment rate is at most 0.06 percentage points higher, which is negligible. The same can be said about the estimates of the effectiveness parameters of the agency. Furthermore, our earlier results on the role of the benefit reform and on the importance of this reform relative to reorganization of the PEA remain completely insensitive. Finally it is interesting to notice that having extended the time horizon and having included the recession, our findings in Table 5 cease to differ across specifications of the error term in auxiliary regressions. Even though we still prefer to report our final results in terms of an interval, alleviation of the sensitivity with respect to specification adds confidence that the true impact of the reform of the PEA lies in the upper range of this interval.

- Predetermined parameters and functional forms

The rate of time preference, set to correspond to the annual discount rate of $2.4 \%$, has not been estimated at any stage of our econometric analysis. Obviously, this parameter plays an important role as the reform affects short- and long-term unemployed workers differently. In Table 6 we present the simulated impact of the reform for varying rates of time preference. In the first two columns of this table, $\rho$ is set to match the annual discount rate of $1.2 \%$; in the last two columns it matches the annual discount rate of $3.6 \%$. The middle two columns repeat our main results reported in Section 4.3 to facilitate easy comparison. 


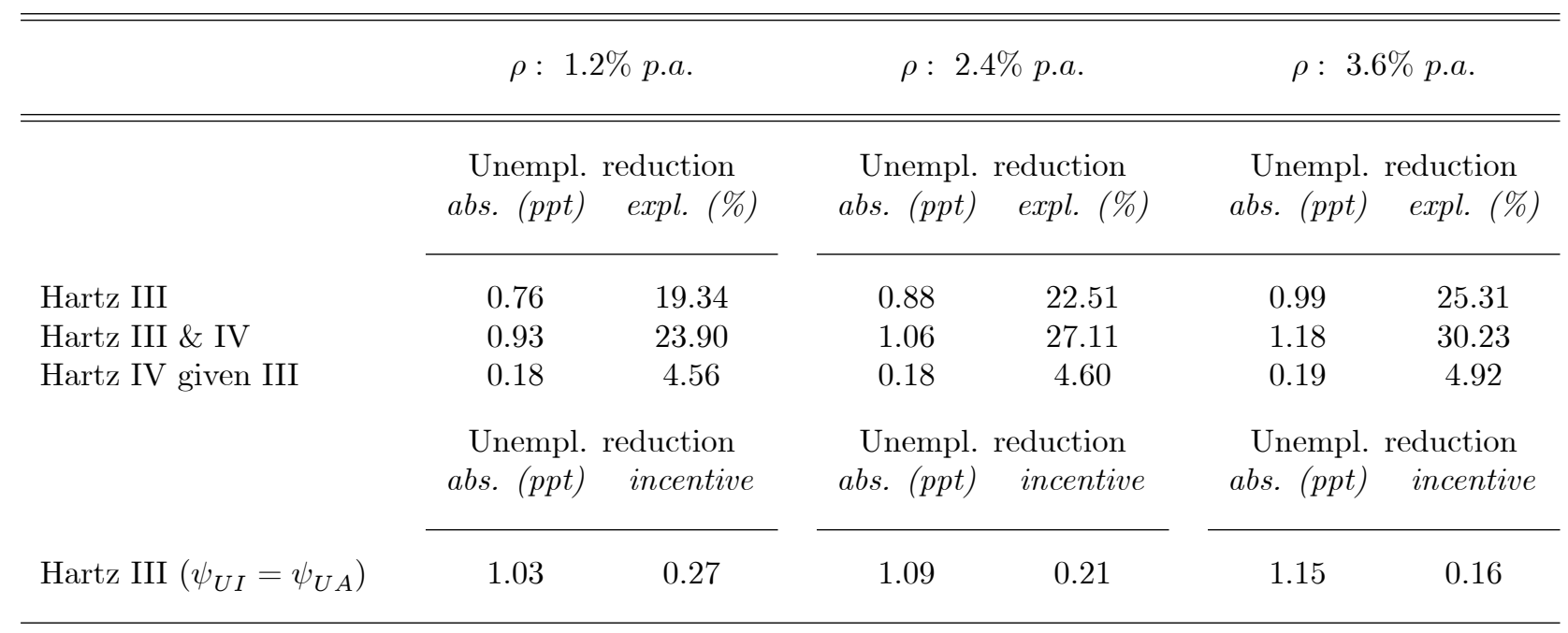

Table 6 Sensitivity to variation in the rate of time preference

From Table 6 we can see that within the reasonable range of variation of parameter $\rho$, the effect of the reform remains fairly stable. The impact of the reform of the agency deviates from the baseline result by 0.11 to 0.12 percentage points and the impact of the benefit reform deviates by just 0.01 percentage point. The same can be said about the quantification of the search disincentive effect induced by a heterogeneous treatment of short- and long-term unemployed workers. First we see that the size of this disincentive effect, as measured by the difference in the decrease of the unemployment rate in the actual $\left(\psi_{U I} \neq \psi_{U A}\right)$ and counterfactual $\left(\psi_{U I}=\psi_{U A}\right)$ designs, goes down as individuals discount future more. However, within the reasonable variation of the rate of time preference, the deviation of the disincentive effect from that in the baseline specification is quite small, making about 0.05 to 0.06 percentage points. We read this as evidence that our evaluation is hardly sensitive to the choice of the rate of time preference and suboptimality of the PEA reform persists.

Next we look into potential restrictiveness of our specification of the costs of search. It is well known (see e.g. Chetty, 2008) that the impact of a benefit reform crucially depends on micro-elasticity of unemployment duration with respect to benefits. In our model, this micro-elasticity is strongly affected by the specification of search costs and of the utility function. In particular, a concave instantaneous utility from unemployment benefits in (2) requires a specification of the disutility of search identical to $\phi(s)$. Only then, as is wellknown in structural labour econometrics, identification at the first stage of our econometric procedure is secured.

We inquire whether this normalization leads to a predicted elasticity that is compatible with estimates of the same elasticity obtained outside our structural model. It turns out that our structural model does a very good job in matching the elasticity of unemployment duration. Using the universe of social security records in Germany, Schmieder et al. (2012) estimate the elasticity of unemployment duration with respect to entitlement to UI. Their point estimates for the period of over 20 years lie between 0.12 and 0.13 with the standard deviations ranging from 0.013 to 0.034 . Computing the long-run elasticity of unemployment 
duration with respect to entitlement to UI computed in our model, we find a value of 0.14 , which is well within the confidence interval of the estimates of Schmieder et al. (2012). This makes us confident that we do not introduce any bias into our reform evaluation through inappropriate parametric form assumptions on the utility and the cost of search functions. Our result is also remarkable because using a different data set and a different methodology we still arrive at the same small elasticity of a four-days increase in mean unemployment duration per additional month of entitlement to UI benefits. Apart from Schmieder et al. (2012) for Germany, such a small effect of about three days per additional month of entitlement to UI is also reported by Lalive (2008) for Austria.

- How large were UA cuts and simulation of Hartz IV

We conclude our sensitivity analysis by looking into the responsiveness of the equilibrium unemployment rate to the assumption, how large cuts of UA benefits under Hartz IV actually were. In a structural equilibrium search framework comparable to ours, Krause and Uhlig (2012) and Krebs and Scheffel (2013) calibrate the effect of UA cuts to find that the Hartz IV reform explains as much as a 2.8 and a 1.4 percentage points decline of the equilibrium unemployment rate, respectively. The size of UA reduction in Krause and Uhlig (2012) varies from $33 \%$ to $76 \%$ of the pre-reform level, depending on worker skills. The size of the UA reduction in Krebs and Scheffel (2013) is uniform, equal to $80 \%$ of the pre-reform level. Reductions of Krause and Uhlig (2012) are endogenous to their model, which makes them dependent on particular assumptions about skill-specific productivity distributions of unemployed workers. Krebs and Scheffel (2013) in contrast rely on the data, taking their reduction from the aggregate OECD statistics.

The reduction of UA benefits in the present paper is taken directly from the microdata (see p. 20 for details). With an average reduction of approximately 7\%, it embodies an important feature of the reform of UA benefits: there were winners and losers. The existence of winners, i.e. those who have experienced an increase of UA payments, and losers, i.e. those whose UA benefits went down, has been documented by the Institute for Employment Research at the stage of computing the amount of funds needed to implement the reform (Bloß and Rudolph, 2005) and by the German Institute for Economic Research during the evaluation of post-reform outcomes (Goebel and Richter, 2007). Winners of the reform are low-wage earners as their benefits according to the former proportional system of UA benefits would be lower than the flat Hartz IV amount. While the amount of winners and losers was roughly equal, the loss of losers was higher than the gain of winners (Bloß and Rudolph, 2005), which has generated a reduction of UA benefits on average.

The difference between the aggregate reductions reported by the OECD and the disaggregate reductions/increases that can be found in the German microdata explains big part of the difference between the predictions of Krebs and Scheffel (2013) and this paper. Implementing the UA reduction of Krebs and Scheffel (2013) in our model, we find that the benefit reform accounts for 0.51 percentage points reduction of the equilibrium unemployment rate. Taking the UA reductions of Krause and Uhlig (2012), we generate a reduction of as much as 1.51 percentage points. This shows that an evaluation attests ineffectiveness if the cut of UA benefits is assumed to be very weak. Given the documented existence of winners and losers, which leads to quite modest UA cuts on average indeed, we think that the impact of the benefit reform is in fact rather low. 
Finally, another factor that may explain the discrepancy between our result and that of Krebs and Scheffel (2013) is the size of the elasticity of unemployment duration with respect to UI benefits. Unfortunately the estimates of this elasticity for Germany are not available in the empirical literature, ${ }^{25}$ which makes Krebs and Scheffel (2013) choose the value of the US. Using our model we can compute that $1 \%$ reduction of UI benefit leads to an increase of the average hazard rate from unemployment to job by $0.2 \%$, which is lower than $0.9 \%$ taken by Krebs and Scheffel (2013). Careful estimation of this elasticity to validate our prediction seems to be extremely interesting. Yet, since our model very closely predicts the elasticity of unemployment duration with respect to extension of entitlement to UI, as shown above, we expect that such estimates should also lie in a ballpark of $0.2 \%$.

\subsection{Reform implications}

What do we learn from this analysis for future reforms? There is a discussion in Germany on a second Hartz-type reform and, much more importantly, there is a discussion at the European level on how to fight the highest unemployment rates in the Euro area ever since the Euro has been introduced. ${ }^{26}$ How can policy measures be informed by our findings?

In some trivial sense, anything that increases the outflows from and reduces the inflows into unemployment is desirable. It is less trivial to suggest measures that actually increase outflows and reduce inflows. The most challenging task consists in quantifying the effects of the suggested measures. Our analysis makes a strong case for an increased effectiveness of the PEA.

What speaks in favour of more effective PEA as opposed to a cut of benefits for long-term unemployed? First, the strong direct effect on the increase of outflows from unemployment. A more efficient PEA does not only increase outflow of long-term unemployed workers - once appropriately tuned, it benefits all unemployed workers. Second, the neutrality of a such a policy measure with respect to distributional considerations. While a cut of benefits for long-term (or all) unemployed workers should increase outflows (if only modestly as we have found), it increases income inequality and poverty.

Is there a direct recommendation for "any" country with high unemployment? We would say no when it comes to detailed reform measures. Our findings strongly suggest, however, that any country should first look into possibilities of making its PEA more effective before thinking about reducing unemployment benefits. From reading descriptions of the reform of the Federal Employment Agency in Germany, the conclusion on which components of this reform were the most important ones is as follows. (i) There is one contact person for all aspects related to unemployment for the unemployed worker. (ii) Short questions are relegated to call-centers. (iii) More time-intensive consultations are by appointment only, reducing considerably waiting times in the agency. (iv) Characteristics of an unemployed worker and parameters of an open vacancy are standardized to facilitate quicker matching by the case-worker. ${ }^{27}$ (v) The number of unemployed managed by a caseworker is reduced to

\footnotetext{
${ }^{25}$ See Schmieder at al., (2012) for literature review.

${ }^{26}$ See e.g. the new release 50/2013 of 2 April 2013 by Eurostat.

${ }^{27}$ An impressive description, albeit in German, is by Weise (2011), the current head of the Federal Employment Agency. It strongly makes the case that the reorganization of all work-flows turned an administrative bureaucracy (that became fraudulent in parts of its activities) into a customer (i.e. employee and employer)
} 
the benchmark of at most 150 , of which at most 75 are under age of 25 years. (vi) Priority is given to workers above the age of $50{ }^{28}$ The Annual Report of the Federal Employment Agency (Bundesagentur für Arbeit, 2013, p. 43) provides empirical confirmation that the quantitative benchmarks in (v) have actually been met, though only in 2012 .

The implication of homogeneous versus heterogeneous impact design of the reform should not be forgotten as well. As our estimates indicate, the PEA reform would have had a higher effect on the reduction of unemployment if short- and long-term unemployed would have benefited equally. Thus, from a design perspective, the reform should probably not condition on unemployment duration.

\section{Conclusions}

We evaluate the impact of a reform of a public employment agency on unemployment in a typical welfare state economy. For this purpose we use a version of a Mortensen-Pissarides matching model extending it for a time-dependent matching effectiveness of the agency.

In our theoretical model, we first demonstrate that an increase in matching effectiveness of the agency does not necessarily lead to a reduction of the unemployment rate. This is our intertemporal unemployment paradox. It occurs when there is a preferential treatment of long-term unemployed workers. If long-term unemployed workers are treated more efficiently in comparison to the short-term unemployed, the latter anticipate the improvement of treatment in the future, which reduces their current search effort. The combination of discouraged search activity of the short-term unemployed workers and boosted search activity of the long-term unemployed workers has an ambiguous net effect on the aggregate unemployment rate.

Second, we structurally estimate the impact of the reform of the public employment agency, aimed at improving matching effectiveness of the agency for short- and long-term unemployed workers in Germany. The design of this reform, also known as Hartz III reform, treated short- and long-term unemployed workers differently. Using estimation by indirect inference, we find that the improvement of the public employment agency has substantially contributed to the reduction of unemployment in Germany. Comparing pre- and post-reform steady states, the reform of the agency becomes responsible for the fall of the equilibrium unemployment rate by 0.69 to 0.88 percentage points. This explains from $17.6 \%$ to $22.5 \%$ of the observed post-Hartz decline in German unemployment.

Third, we find that the present design of the reform, which has turned out to favour long-term unemployed workers about three times more than short-term ones, appears to be suboptimal. If less attention had been paid to long-term unemployed workers, the unemployment rate would have fallen even more as a result of the PEA reform. This suggests the policy conclusion that reforms of public employment agencies should not make such big differences between different types of unemployed workers. The mechanism behind the result is again the intertemporal unemployment paradox.

Fourth, we make a strong case for improvement of the public employment agency as opposed to reduction of allegedly generous unemployment benefits. We compare the reform

\footnotetext{
oriented service center.

${ }^{28}$ These benchmarks are from SGB II $\S$ 44c paragraph 4 in Bundesgesetzblatt 2011, part I, Nr.23, p.852-891.
} 
of the agency to the reduction of benefit generosity which took place in Germany under arrangements of the so-called Hartz IV reform, following Hartz III. We show that the benefit reform, which assumed shortening of entitlement to unemployment insurance and moderate cuts of unemployment assistance benefits, has indeed brought a very modest result. It has added only 0.18 to 0.20 percentage points to further fall of the equilibrium unemployment rate, explaining just $4.6 \%$ to $5.1 \%$ of the observed post-Hartz unemployment decline. Given the amount of public debates that were surrounding the reduction of benefit generosity, we conclude that benefit cuts big enough to generate the effect comparable to the reform of the agency lie very likely outside the range of possible political compromise.

We see the primary contribution of this paper in discovering a substantial unemploymentreducing potential in typical welfare states. This potential is locked inside inefficient public employment agencies. There exists a rich literature that addresses different labour market institutions of a welfare state and analyzes how reforming these institutions can help us reduce unemployment. Unemployment compensation systems, trade unions, labour taxes or subsidies and employment protection are all among the most frequently analyzed institutions. Surprising as it is, in this list one cannot find the public employment agency itself. With our findings that about $1 / 5$ of the post-reform decline in unemployment can be attributed to their reorganization, public employment agencies and their modernization must not be overlooked by policy makers and by academic researchers alike.

Future work would have to extend the present setup by allowing for an endogenous separation rate and job-to-job transitions. As discussed on p. 3.1, we believe that an estimated version of the present model allowing for an endogenous separation rate would yield a somewhat lower effect on the reduction of the unemployment rate. One could equally conjecture, however, that the effect would not play a significant role. Resolving this issue would be a highly exciting research project for the future.

\section{Appendix}

\section{A.1 The literature on Hartz reforms}

In principle, all labour market regulations and their changes are documented in the corresponding laws ('Sozialgesetzbüchern'). As a starting point on labour market policy and how it is encoded in the law, see Keller and Henneberger (2010). Considering the first, second and third packages of the reform, the basic law is "SGB III - Arbeitsförderung" (Bundesgesetzblatt 1997, Teil I, Nr.20, p. 595-689). Amendments to this law through Hartz I, Hartz II and Hartz III are in "Erstes Gesetz für Moderne Dienstleistungen am Arbeitsmarkt" (Bundesgesetzblatt 2002, Teil I, Nr.87, p. 4607-4616), "Zweites Gesetz für Moderne Dienstleistungen am Arbeitsmarkt" (Bundesgesetzblatt 2002, Teil I, Nr.87, p. 4621-4636) and "Drittes Gesetz für Moderne Dienstleistungen am Arbeitsmarkt" (Bundesgesetzblatt 2003, Teil I, Nr.65, p. 2849-2886), respectively. Regarding the fourth package, the basic law is "SGB II - Grundsicherung für Arbeitssuchende" (Bundesgesetzblatt 2003, Teil I, Nr.66, p. 2955-2971). This law is the first article of the "Viertes Gesetz für Moderne Dienstleistungen am Arbeitsmarkt", i.e. of Hartz IV. Moreover, amendments to SGB III by Hartz IV are in "Viertes Gesetz für Moderne Dienstleistungen am Arbeitsmarkt" (Bundesgesetzblatt 
2003, Teil I, Nr.65, p. 2971-2975). Distilling out the changes due to the Hartz reforms from reading these laws is a research project on its own. This is why we additionally rely on the literature.

The existing literature is huge and ranges from newspaper to scientific articles. Most of these articles have a strong policy and political orientation. Here is a list of articles on which we base our summary in the main text. Kaltenborn et al. (2006a) provide a summary of the structure and evaluations of Hartz I, II and III. The long version is the report by the Bundesregierung (2005). An even more extensive version is the report by the Bundesministerium für Arbeit und Soziales (2006). Based on the latter, Kaltenborn et al. (2006b) provide a list of various measures introduced by the reform (see their Table 1).

In addition, the core elements of the Hartz reforms are worked out by Jacobi and Kluve (2007). Weise (2011), the head of the "Bundesagentur für Arbeit", provides a clear description of the effects of Hartz III with respect to the reorganization of the German PEA. Schuetz and Oschmiansky (2006) also emphasize the importance of the reorganization of the German PEA. Heyer et al. (2012) provide an overview on active labour market policy aspects of the reform.

A website providing a good review of reform contents (despite not being completely up to date) is WIPOL (2006).

\section{A.2 Data}

In what follows we provide a brief overview of the data used at the first and second stages of our structural estimation procedure.

- First stage

Table A.1 provides the complete characterization of the steady state before any reform. Sources for this table are the German Socio-Economic Panel (GSOEP, www.gsoep.de) for wage and benefit data along with all group characteristics; the IAB (www.iab.de) for vacancy and unemployment data and Launov and Wälde (2013) for the sample taken from GSOEP and all the structural parameters. All monetary values are in Euros of 2005.

The skill distribution $\{\pi(k)\}_{k=1}^{K}$ in the economy relates to the sample taken from the entire population of working age individuals. The rest of the observed data, except of labour market tightness and unemployment rate, stems from the flow sample of entrants into fulltime employment and unemployment between 01.2001 and 12.2003. Reported UA benefits $\tilde{b}_{U A, k}$ are conditional on eligibility to UI benefits (an event happening with probability $\pi_{k}^{U I}$ ) and on passing the means test upon expiration of entitlement to UI (an event happening with probability $\left.\pi^{U A}\right)$. Expected benefit $b_{U A, k}$ used in the quantification of the pre-reform steady state is therefore defined as $b_{U A, k} \equiv \pi_{k}^{U I} \pi^{U A} \tilde{b}_{U A, k}$. The statutory replacement rate is approximately 0.55 of the average net wage of previous employment, such that $\tilde{b}_{U A, k} \equiv$ $0.55 * w_{k}$. Entitlement length $\bar{s}$ is computed using the observed duration of the contribution period in the last employment spell and age-dependent rules before Hartz IV. Parameters $\left\{\lambda_{k}, \eta_{0, k}\right\}_{k=1}^{K}$ and $\left\{\alpha, \sigma, \pi^{U A}, \pi^{\chi}, \nu\right\}$ are structurally estimated. For methodological discussion of the prediction of parameters $\left\{A_{k}, \gamma_{k}\right\}_{k=1}^{K}$ and of the equilibrium solution for $\left\{w_{k}, u_{k}, \theta_{k}\right\}_{k=1}^{K}$ and $\kappa$ see Launov and Wälde (2013). 


\begin{tabular}{|c|c|c|c|c|c|c|c|}
\hline & & high & $\begin{array}{l}\text { West } \\
\text { medium }\end{array}$ & low & high & $\begin{array}{c}\text { East } \\
\text { medium }\end{array}$ & low \\
\hline \multirow{2}{*}{$\begin{array}{l}\text { observed } \\
\text { parameters }\end{array}$} & $\pi(k)$ & 0.1989 & 0.4094 & 0.1688 & 0.0730 & 0.1202 & 0.0297 \\
\hline & $\pi_{k}^{U I}$ & 0.3913 & 0.5068 & 0.3696 & 0.6757 & 0.7023 & 0.4412 \\
\hline \multirow{3}{*}{$\begin{array}{l}\text { policy } \\
\text { parameters }\end{array}$} & $\bar{s}_{k}$ & 15 & 11 & 11 & 12 & 12 & 13 \\
\hline & $\tilde{b}_{U A, k}$ & 938 & 615 & 498 & 844 & 624 & 464 \\
\hline & $\lambda_{k}$ & 0.0055 & 0.0080 & 0.0124 & 0.0139 & 0.0203 & 0.0282 \\
\hline \multirow{3}{*}{$\begin{array}{l}\text { estimated and } \\
\text { predicted parameters }\end{array}$} & $\eta_{0, k}$ & 0.0189 & 0.0224 & 0.0204 & 0.0268 & 0.0360 & 0.0314 \\
\hline & $A_{k}$ & 2155 & 1473 & 1368 & 2130 & 1588 & 1276 \\
\hline & $\gamma_{k}$ & 15633 & 14136 & 13916 & 27563 & 22464 & 8193 \\
\hline \multirow{3}{*}{$\begin{array}{l}\text { equilibrium } \\
\text { values }\end{array}$} & $w_{k}$ & 1705 & 1118 & 905 & 1535 & 1134 & 843 \\
\hline & $\theta_{k}$ & 0.46 & 0.27 & 0.16 & 0.11 & 0.08 & 0.19 \\
\hline & $u_{k}$ & $4.6 \%$ & $7.4 \%$ & $15.9 \%$ & $15.1 \%$ & $19.1 \%$ & $22.1 \%$ \\
\hline estimated & $\alpha$ & 0.4203 & $\pi^{U A}$ & 0.2398 & $\nu$ & 1.4438 & \\
\hline aggregate parameters & $\sigma$ & 0.7808 & $\pi^{\chi}$ & 0.9228 & & & \\
\hline aggregate & $\kappa$ & 0.0225 & \multirow{2}{*}{\multicolumn{2}{|c|}{$\begin{array}{l}\text { exogenous } \\
\text { parameters }\end{array}$}} & $\rho$ & \multirow{2}{*}{\multicolumn{2}{|c|}{$\begin{array}{l}2.4 \% \text { p.a. } \\
0.5\end{array}$}} \\
\hline equilibrium values & $u$ & $10.7 \%$ & & & $\beta$ & & \\
\hline
\end{tabular}

Table A.1 Characteristics of the pre-reform steady state

Table A.2 reports changes to benefits and entitlement as a consequence of Hartz IV. All values in this table are computed as described on p. 20.

\begin{tabular}{lccccccc}
\hline \hline & \multicolumn{3}{c}{ West } & \multicolumn{3}{c}{ East } \\
& high & medium & low & high & medium & low \\
\hline \hline ALG II as a share of UA & 0.95 & 0.95 & 1.15 & 0.70 & 0.95 & 1.3 \\
Entitlement cut (months) & 3 & 1 & 1 & 1 & 2 & 2 \\
\hline
\end{tabular}

Table A.2 Specification of the Hartz IV reform

- Second stage

The data for the second stage comprise stocks of matches, registered unemployed and vacancies at the regional level. The data source is the IAB (www.iab.de) reports. Figure A.1 plots the data aggregated to the country level for the illustrative purpose. Its upper part shows the evolution of unemployment and matches separately for short-term and long-term unemployed over the period from 2000 to 2009. Its lower part plots the dynamics of vacancies over the same period. Vertical axes display thousands of workers (for unemployment and matches) and thousands of idle jobs (for vacancies). 

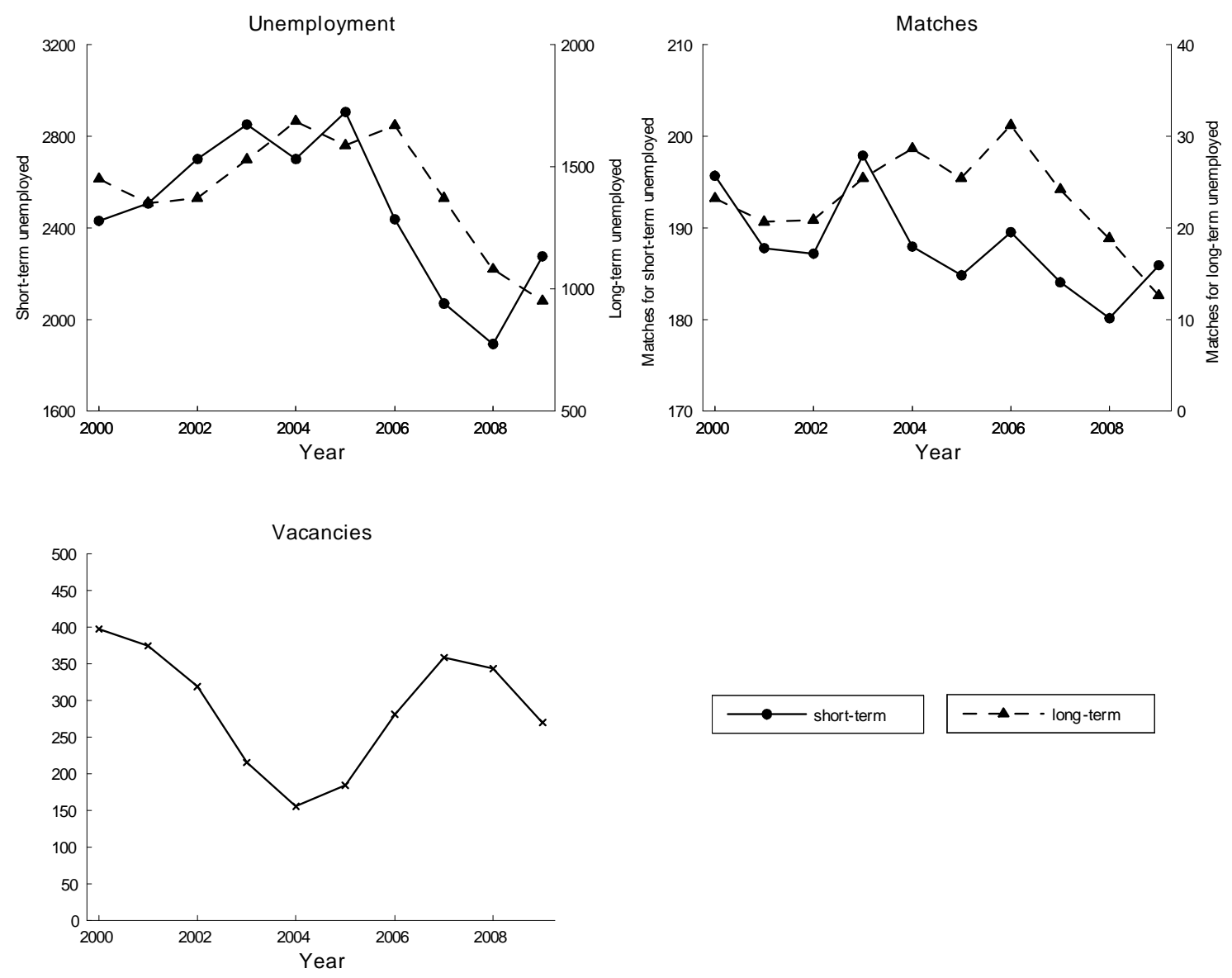

Figure A.1 Stocks of matches, unemployment and vacancies

These data define as short-term unemployed all individuals whose duration of unemployment does not exceed one year. The stock of vacancies used in our analysis contains only "normal" vacancies, i.e. regular jobs with contributions to social security system. These exclude marginal employment (e.g. that under arrangements of Hartz II), seasonal and irregular employment. Controls for structural breaks in unemployment statistics are explained in the main text. For further details on the data see Klinger and Rothe (2012), who use the same time series (at a monthly frequency)

\section{A.3 Auxiliary regressions}

Table A.3 reports estimation results on auxiliary regressions. Its upper and lower blocks deal with matches for short- and long-term unemployed, respectively. In both blocks columns (1)-(3) show the estimates from the specification without market-specific effects, (4)-(6) relate to specification with market-specific effects, and (7)-(9) report the estimates form the specification with market-specific effects and $\mathrm{AR}(1)$ process in the error term. Within each 
Dependent variable: log-outflows from short-term unemployment

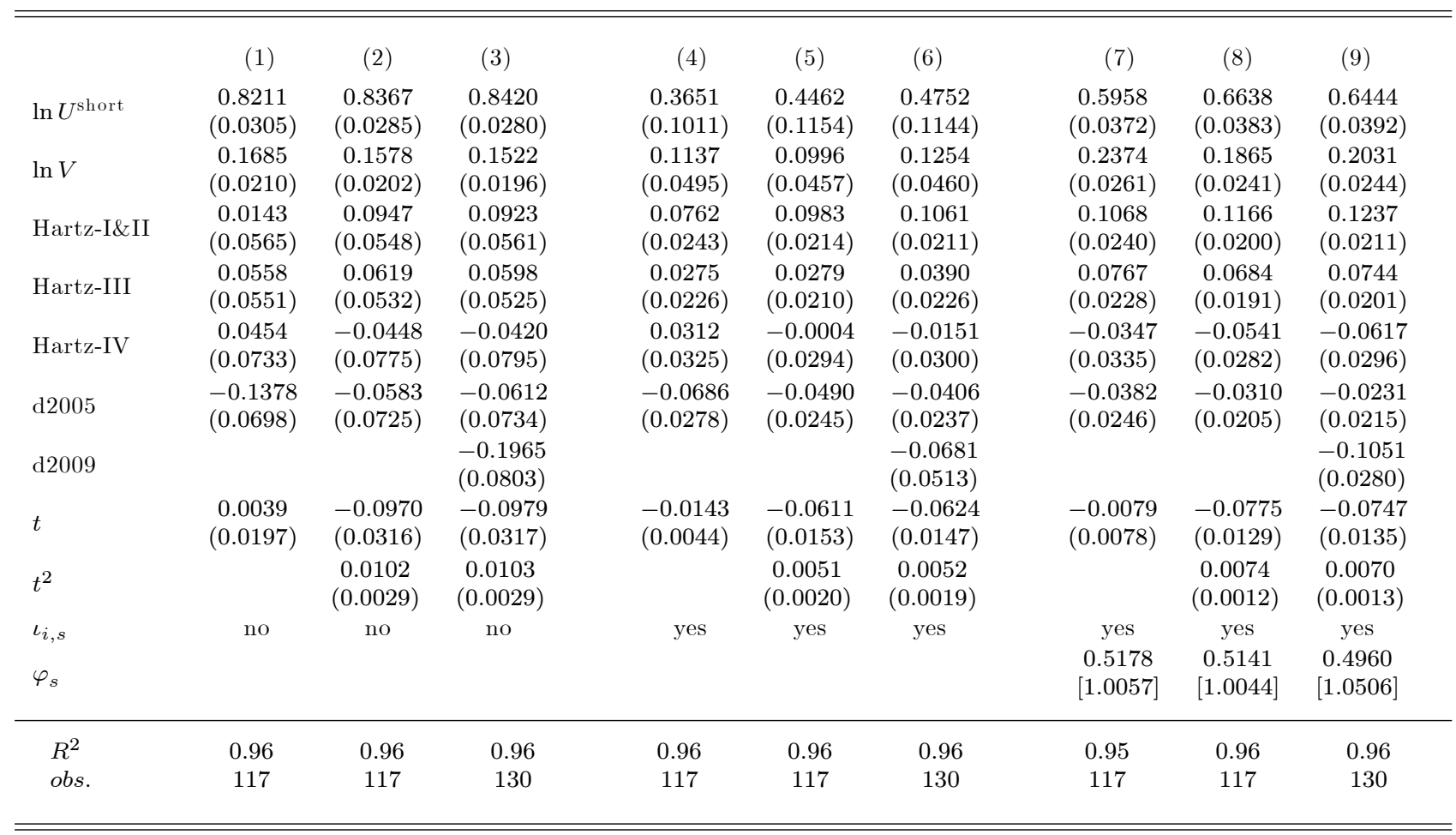

Dependent variable: log-outflows from long-term unemployment

\begin{tabular}{|c|c|c|c|c|c|c|c|c|c|}
\hline & (1) & (2) & $(3)$ & (4) & $(5)$ & (6) & (7) & (8) & (9) \\
\hline $\ln U^{\text {long }}$ & $\begin{array}{c}0.9021 \\
(0.0222)\end{array}$ & $\begin{array}{c}0.9023 \\
(0.0221)\end{array}$ & $\begin{array}{c}0.9017 \\
(0.0215)\end{array}$ & $\begin{array}{c}0.9438 \\
(0.0532)\end{array}$ & $\begin{array}{c}0.9475 \\
(0.0548)\end{array}$ & $\begin{array}{c}0.9307 \\
(0.0552)\end{array}$ & $\begin{array}{c}0.9168 \\
(0.0364)\end{array}$ & $\begin{array}{c}0.9202 \\
(0.0378)\end{array}$ & $\begin{array}{c}0.9065 \\
(0.0359)\end{array}$ \\
\hline $\ln V$ & $\begin{array}{c}0.0539 \\
(0.0161)\end{array}$ & $\begin{array}{c}0.0538 \\
(0.0157)\end{array}$ & $\begin{array}{c}0.0537 \\
(0.0152)\end{array}$ & $\begin{array}{c}0.0024 \\
(0.0318)\end{array}$ & $\begin{array}{c}0.0012 \\
(0.0327)\end{array}$ & $\begin{array}{c}0.0159 \\
(0.0294)\end{array}$ & $\begin{array}{c}0.0407 \\
(0.0287)\end{array}$ & $\begin{array}{c}0.0394 \\
(0.0290)\end{array}$ & $\begin{array}{c}0.0500 \\
(0.0284)\end{array}$ \\
\hline Hartz-I\&II & $\begin{array}{c}0.1632 \\
(0.0467)\end{array}$ & $\begin{array}{c}0.1641 \\
(0.0485)\end{array}$ & $\begin{array}{c}0.1633 \\
(0.0487)\end{array}$ & $\begin{array}{c}0.1361 \\
(0.0354)\end{array}$ & $\begin{array}{c}0.1370 \\
(0.0340)\end{array}$ & $\begin{array}{c}0.1438 \\
(0.0343)\end{array}$ & $\begin{array}{c}0.1510 \\
(0.0350)\end{array}$ & $\begin{array}{c}0.1515 \\
(0.0352)\end{array}$ & $\begin{array}{c}0.1563 \\
(0.0351)\end{array}$ \\
\hline Hartz-III & $\begin{array}{c}0.0666 \\
(0.0427)\end{array}$ & $\begin{array}{c}0.0654 \\
(0.0485)\end{array}$ & $\begin{array}{c}0.0666 \\
(0.0432)\end{array}$ & $\begin{array}{c}0.0417 \\
(0.0280)\end{array}$ & $\begin{array}{c}0.0379 \\
(0.0288)\end{array}$ & $\begin{array}{c}0.0487 \\
(0.0277)\end{array}$ & $\begin{array}{c}0.0601 \\
(0.0333)\end{array}$ & $\begin{array}{c}0.0581 \\
(0.0339)\end{array}$ & $\begin{array}{c}0.0654 \\
(0.0334)\end{array}$ \\
\hline Hartz-IV & $\begin{array}{c}0.0288 \\
(0.0737)\end{array}$ & $\begin{array}{c}0.0169 \\
(0.1319)\end{array}$ & $\begin{array}{c}0.0289 \\
(0.0734)\end{array}$ & $\begin{array}{c}0.0785 \\
(0.0482)\end{array}$ & $\begin{array}{c}0.0514 \\
(0.0455)\end{array}$ & $\begin{array}{c}0.0652 \\
(0.0450)\end{array}$ & $\begin{array}{c}0.0409 \\
(0.0603)\end{array}$ & $\begin{array}{c}0.0249 \\
(0.0757)\end{array}$ & $\begin{array}{c}0.0323 \\
(0.0607)\end{array}$ \\
\hline d 2005 & $\begin{array}{l}-0.0581 \\
(0.0621)\end{array}$ & $\begin{array}{l}-0.0483 \\
(0.1086)\end{array}$ & $\begin{array}{l}-0.0582 \\
(0.0613)\end{array}$ & $\begin{array}{l}-0.0992 \\
(0.0554)\end{array}$ & $\begin{array}{l}-0.0771 \\
(0.0545)\end{array}$ & $\begin{array}{l}-0.0881 \\
(0.0540)\end{array}$ & $\begin{array}{l}-0.0679 \\
(0.0472)\end{array}$ & $\begin{array}{l}-0.0549 \\
(0.0601)\end{array}$ & $\begin{array}{l}-0.0607 \\
(0.0475)\end{array}$ \\
\hline $\mathrm{d} 2006$ & $\begin{array}{c}0.0904 \\
(0.0496)\end{array}$ & $\begin{array}{c}0.0971 \\
(0.0760)\end{array}$ & $\begin{array}{c}0.0905 \\
(0.0492)\end{array}$ & $\begin{array}{c}0.0692 \\
(0.0440)\end{array}$ & $\begin{array}{c}0.0840 \\
(0.0400)\end{array}$ & $\begin{array}{c}0.0752 \\
(0.0420)\end{array}$ & $\begin{array}{c}0.0856 \\
(0.0314)\end{array}$ & $\begin{array}{c}0.0935 \\
(0.0386)\end{array}$ & $\begin{array}{c}0.0895 \\
(0.0316)\end{array}$ \\
\hline $\mathrm{d} 2009$ & & & $\begin{array}{l}-0.2435 \\
(0.0485)\end{array}$ & & & $\begin{array}{l}-0.2453 \\
(0.0274)\end{array}$ & & & $\begin{array}{l}-0.2444 \\
(0.0298)\end{array}$ \\
\hline$t$ & $\begin{array}{c}-0.0222 \\
(0.0176)\end{array}$ & $\begin{array}{c}-0.0254 \\
(0.0289)\end{array}$ & $\begin{array}{l}-0.0222 \\
(0.0182)\end{array}$ & $\begin{array}{l}-0.0208 \\
(0.0094)\end{array}$ & $\begin{array}{l}-0.0282 \\
(0.0108)\end{array}$ & $\begin{array}{c}-0.0213 \\
0.0095\end{array}$ & $\begin{array}{l}-0.0212 \\
(0.0131)\end{array}$ & $\begin{array}{c}-0.0269 \\
(0.0209)\end{array}$ & $\begin{array}{c}-0.0217 \\
0.0132\end{array}$ \\
\hline$t^{2}$ & & $\begin{array}{c}0.0005 \\
(0.0040)\end{array}$ & & & $\begin{array}{c}0.0012 \\
(0.0011)\end{array}$ & & & $\begin{array}{c}0.0008 \\
(0.0023)\end{array}$ & \\
\hline$\iota_{i, l}$ & no & no & no & yes & yes & yes & yes & yes & yes \\
\hline$\varphi_{l}$ & & & & & & & $\begin{array}{c}0.3775 \\
{[1.3327]}\end{array}$ & $\begin{array}{c}0.3778 \\
{[1.3308]}\end{array}$ & $\begin{array}{c}0.3851 \\
{[1.3374]}\end{array}$ \\
\hline$R^{2}$ & 0.97 & 0.97 & 0.98 & 0.97 & 0.97 & 0.98 & 0.98 & 0.98 & 0.98 \\
\hline obs. & 117 & 117 & 130 & 117 & 117 & 130 & 117 & 117 & 130 \\
\hline
\end{tabular}

Table A.3 Auxiliary regressions for the real data 
specification, the first column shows the results with linear trend, the second column shows the results with quadratic trend and the third column extends the time horizon adding the recession together with the corresponding dummy variable. Standard errors are in parenthesis. For columns (1)-(6) standard errors are bootstrapped, with 5000 replications. Values of the Durbin-Watson test statistic for significance of the autoregression coefficient in columns (7)-(9) are in square brackets.

From Table A.3 we can see that for the short-term unemployed workers, the quadratic trend is supported by all specifications. For the long-term unemployed, only the linear trend is supported and this support appears only in the specifications with market-specific effects. Significance of the linear trend is strong in the regressions without autoregressive term and weak in the regressions with autoregressive terms. ${ }^{29}$ Regarding the estimates of the autoregression coefficient for short- and long term unemployed, despite the values of the Durbin-Watson statistic being low enough to support the existence of the autoregressive process, we lack the relevant critical values due to too small number of observations in the cross-section. Thus, from a purely formal point of view we can neither establish nor refute $\mathrm{AR}(1)$ process in the error term. For this reason, we need to perform a sensitivity analysis. For our baseline specification (see Table 1), we chose a regression with a quadratic term and an $\mathrm{AR}(1)$ process in the errors for the short-term unemployed workers and a regression with a linear term and an $\mathrm{AR}(1)$ process in the errors for the long-term unemployed workers. For the sensitivity analysis (see Table 3), we remove the autoregressive terms from the errors of both auxiliary regression equations.

\section{A.4 Other appendices}

- Web appendix: http://www.empirical.economics.uni-mainz.de/Dateien/PEAwebapp.pdf

- Code and data: http://www.empirical.economics.uni-mainz.de/Dateien/PEAcd.zip

\section{Acknowledgements}

Earlier version of this paper was circulated under the title "Thumbscrews for agencies or for individuals? How to reduce unemployment". We are grateful to seminar participants in Bielefeld, Berlin (Humboldt University), Düsseldorf (IMK), Mainz, Munich, Nürnberg (IAB), Trier and at the IMF, participants of the SaM Annual Conferences in Mainz and Aix-en-Provence, workshops and conferences in Brussels (KVAB), Eltville (IAB / Deutsche Bundesbank), Hamburg, Mannheim, Munich, Paris (Sciences Po) and Rennes (ENSAI), to Björn Brügemann, Chris Holzner, Philipp Kircher, Francis Kramarz, Michael Krause, Tom Krebs, Bruno van der Linden, Christopher Pissarides, Eric Smith, Gianluca Violante for very useful discussions and suggestions. Special thanks are to Sabine Klinger and Thomas Rothe for making their data from Klinger and Rothe (2012) accessible to us, to Fred Henneberger for his guidance in understanding the juridical aspects of labour market policy and to Sylwia Bialek for excellent research assistance. We are indebted to two anonymous referees and the editor for very constructive and useful comments. Andrey Launov gratefully acknowledges

\footnotetext{
${ }^{29}$ The linear trend is marginally significant at $10 \%$ level (p-value of 0.099 ) in column (9) and marginally insignificant at $10 \%$ level (p-value of 0.105 ) in column (7).
} 
financial support from the German Science Foundation under grant LA2389/2-1 and research hospitality of the Center for Economic Studies (Munich). Klaus Wälde is indebted to the Gutenberg Research College for a research fellowship from 2009 to 2014.

\section{References}

Albrecht, J. and Vroman, S.: 2005, Equilibrium search with time-varying unemployment benefits, Economic Journal 115, 631-648.

Bagger, J., Fontaine, F., Postel-Vinay, F. and Robin, J.-M.: 2014, Tenure, experience, human capital, and wages: A tractable equilibrium search model of wage dynamics, American Economic Review 104, 1551-1596.

Bentolila, S., Cahuc, P., Dolado, J. and Le Barbanchon, T.: 2012, Two-tier labour markets in the Great Recession: France versus Spain, The Economic Journal 122, F155-F187.

Blanchard, O. and Diamond, P.: 1989, The Beveridge curve, Brookings Papers on Economic Activity 1, 1-76.

Blanchard, O. and Diamond, P.: 1994, Ranking, unemployment duration and wages, Review of Economic Studies 61, 417-434.

Blau, D. and Robins, P.: 1990, Job search outcomes for the employed and unemployed, Journal of Political Economy 98, 637-655.

Blau, F. and Kahn, L.: 1999, Institutions and laws in the labor market, in O. Ashenfelter and D. Card (eds), Handbook of Labor Economics, Vol. 3a, Elsevier Science B.V., chapter 25, pp. 1399-1461.

Bloß, K. and Rudolph, H.: 2005, Verlierer, aber auch Gewinner, IAB Kurzbericht 17, 1-6.

Boeri, T. and Burda, M.: 2009, Preferences for collective versus individualised wage setting, The Economic Journal 119, 1440-1463.

Borowczyk-Martins, D., Jolivet, G. and Postel-Vinay, F.: 2013, Accounting for endogeneity in matching function estimation, Review of Economic Dynamics 16, 440-451.

Bundesagentur für Arbeit: 2013, SGB II - Jahresbericht 2012. Bundesagentur für Arbeit.

Bundesministerium für Arbeit und Soziales: 2006, Die Wirksamkeit moderner Dienstleistungen am Arbeitsmarkt. Bericht 2006 des Bundesministeriums für Arbeit und Soziales zur Wirkung der Umsetzung der Vorschläge der Kommission Moderene Dienstleistungen am Arbeitsmarkt.

Bundesregierung: 2005, Bericht 2005 der Bundesregierung zur Wirksamkeit moderner Dienstleistungen am Arbeitsmarkt. Bundesregierung.

Cahuc, P. and Lehmann, E.: 2000, Should unemployment benefits decrease with the unemployment spell?, Journal of Public Economics 77, 135-153. 
Cahuc, P. and Malherbet, F.: 2004, Unemployment compensation finance and labor market rigidity, Journal of Public Economics 95, 481-501.

Chetty, R.: 2008, Moral hazard versus liquidity and optimal unemployment insurance, Journal of Political Economy 116, 173-234.

Chéron, A. and Langot, F.: 2010, On-the-job search equilibrium with endogenous unemployment benefits, Labour Economics 17, 383-391.

Coles, M. and Masters, A.: 2006, Optimal unemployment insurance in a matching equilibrium, Journal of Labor Economics 24, 109-138.

Fahr, R. and Sunde, U.: 2009, Did the Hartz reforms speed-up the matching process? A macro-evaluation using empirical matching functions, German Economic Review 10, $284-316$.

Fernández-Blanco, J. and Preugschat, E.: 2015, xxx. Universitat Autònoma de Barcelona, mimeo.

Flinn, C.: 2006, Minimum wage effects on labor market outcomes under search, matching, and endogenous contact rates, Econometrica 74, 1013-1062.

Fougère, D., Pradel, J. and Roger, M.: 2009, Does the public employment service affect search effort and outcomes?, European Economic Review 53, 846-869.

Goebel, J. and Richter, M.: 2007, Nach der Einführung von Arbeitslosengeld II: Deutlich mehr Verlierer als Gewinner unter den Hilfeempfängern, DIW Wochenbericht 74, 753761.

Gourieroux, C., Monfort, A. and Renault, E.: 1993, Indirect inference, Journal of Applied Econometrics 8, S85-S118.

Heyer, G., Koch, S., Stephan, G. and Wolff, J.: 2012, Evaluation der aktiven Arbeitsmarktpolitik: Ein Sachstandsbericht für die Instrumentenreform 2011, Zeitschrift für ArbeitsmarktForschung 45, 41-62.

Holzer, H.: 1988, Search method use by unemplyoed youth, Journal of Labor Economics 6, $1-20$.

Immervoll, H., Kleven, H., Kreiner, C. and Saez, E.: 2007, Welfare reform in European countreis: A microsimulation analysis, The Economic Journal 117, 1-44.

Jacobi, L. and Kluve, J.: 2007, Before and after the Hartz reforms: The performance of active labour market policy in Germany, Zeitschrift für ArbeitsmarktForschung 40, 45-64.

Jung, P. and Kuhn, M.: 2014, Labor market institutions and worker flows: Comparing Germany and the U.S., The Economic Journal 124, 1317-1342.

Kaltenborn, B., Knerr, P. and Schiwarov, J.: 2006a, Hartz: Bilanz der Arbeitsmarkt- und Beschäftigungspolitik, Blickpunkt Arbeit und Wirtschaft 12, 1-7. 
Kaltenborn, B., Knerr, P. and Schiwarov, J.: 2006b, Hartz: Förderstrukturen, Blickpunkt Arbeit und Wirtschaft 11, 1-6.

Keller, B. and Henneberger, F.: 2010, Arbeitsmarktpolitik, Gabler Wirtschaftslexikon, 17th edn, Springer Gabler Verlag, pp. 177-183. online: http://wirtschaftslexikon.gabler.de/Archiv/974/arbeitsmarktpolitik-v13.html.

Klinger, S. and Rothe, T.: 2012, The impact of labour market reforms and economic performance on the matching of the short-term and long-term unemployed, Scottish Journal of Political Economy 59, 90-114.

Krause, M. and Uhlig, H.: 2012, Transitions in the German labor market: Structure and crisis, Journal of Monetary Economics 59, 64-79.

Krebs, T. and Scheffel, M.: 2013, Macroeconomic evaluation of labor market reform in Germany, IMF Economic Review 61, 664-701.

Krebs, T. and Scheffel, M.: 2014, Labor market reform and the cost of business cycles. University of Mannheim, mimeo.

Lalive, R.: 2008, How do extended benefits affect unemployment duration? A regression discontinuity approach, Journal of Econometrics 142, 785-806.

Launov, A. and Wälde, K.: 2013, Estimating incentive and welfare effects of non-stationary unemployment benefits, International Economic Review 54, 1159-1198.

Lehmann, E. and van der Linden, B.: 2007, On the optimality of search matching equilibrium when workers are risk averse, Journal of Public Economic Theory 9, 867-884.

L'Haridon, O. and Malherbet, F.: 2009, Employment protection reform in search economies, European Economic Review 53, 255-273.

Lise, J.: 2013, On-the-job search and precautionary savings, Review of Economic Studies 80, 1086-1113.

Lockwood, V.: 1991, xxx, Review of Economic Studies xx, xxx-xxx.

Mortensen, D. and Pissarides, C.: 1999, Unemployment responses to 'skill-biased' technology shocks: The role of labour market policy, The Economic Journal 109, 242-265.

Nickell, S. and Layard, R.: 1999, Labour market institutions and economic performance, in O. Ashenfelter and D. Card (eds), Handbook of Labor Economics, Vol. 3c, Elsevier Science B.V., chapter 46, pp. 3029-3084.

OECD: 2014, OECD.StatExtracts. http://stats.oecd.org.

Petrongolo, B. and Pissarides, C.: 2001, Looking into the black box: A survey on the matching function, Journal of Economic Literature 39, 390-431. 
Pissarides, C.: 1979, Job matchings with state employment agencies and random search, The Economic Journal 89, 818-833.

Pissarides, C.: 2000, Equilibrium Unemployment Theory, MIT Press, Cambridge, Massachusetts.

Plesca, M.: 2010, A general equilibrium evaluation of the employment service, Journal of Human Capital 4, 274-329.

Postel-Vinay, F. and Robin, J.-M.: 2002, Equilibrium wage dispersion with worker and employer heterogeneity, Econometrica 70, 2295-2350.

Postel-Vinay, F. and Turon, H.: 2010, On-the-job search, productivity shocks, and the individual earnings process, International Economic Review 51, 599-629.

Pries, M. and Rogerson, R.: 2005, Hiring policies, labor market institutions and labor market flows, Journal of Political Economy 113, 811-839.

Schmieder, J., von Wachter, T. and Bender, S.: 2012, The effects of extended unemployment insurance over the business cycle: Evidence from regression discontinuity estimates over 20 years, Quarterly Journal of Economics 127, 701-752.

Schütz, H. and Oschmiansky, F.: 2006, Arbeitsamt war gestern: Neuausrichtung der Vermittlungsprozesse in der Bundesagentur für Arbeit nach den Hartz-Gesetzen, Zeitschrift für Sozialreform 52, 5-28.

van den Berg, G. and Ridder, G.: 1998, An empirical equilibrium search model of the labor market, Econometrica 66, 1183-1221.

Weber, A. and Mahringer, H.: 2008, Choice and success of job search methods, Empirical Economics 35, 153-178.

Weise, F.-J.: 2011, Der Umbau der Bundesanstalt/Bundesagentur für Arbeit zum modernen Dienstleister, Vierteljahrshefte zur Wirtschaftsforschung 80, 67-78.

WIPOL: 2006, Hartz-Evaluierung. http://www.wipol.de/hartz/evaluierung.htm.

Yashiv, E.: 2004, Macroeconomic policy lessons of labor market frictions, European Economic Review 48, 259-284.

Yavaş, A.: 1994, Middlemen in bilateral search markets, Journal of Labor Economics 12, 406429. 